\title{
Alcohol use and cardiometabolic risk in the UK Biobank: a Mendelian randomization study
}

Joanna Lankester(1), Daniela Zanetti(1), Erik Ingelsson ${ }^{(1,2)}$, Themistocles L. Assimes ${ }^{(1,3)}$

(1) Department of Medicine (Division of Cardiovascular Medicine), Stanford University School of Medicine, Stanford, CA.

(2) GlaxoSmithKline, Inc., Brentford, England, UK.

(3) VA Palo Alto Health Care System, Palo Alto, CA. 


\section{Abstract}

Observational studies suggest alcohol use promotes the development of some adverse cardiometabolic traits but protects against others including outcomes related to coronary artery disease. We used Mendelian randomization to explore causal relationships between the degree of alcohol consumption and several cardiometabolic traits in the UK Biobank. We found carriers of the ADH1B Arg47His variant (rs1229984) reported a $26 \%$ lower amount of alcohol consumption compared to non-carriers. In our one-sample, two-stage least squares analyses of the UK Biobank using rs1229984 as an instrument, one additional drink/day was associated with statistically significant elevated level of systolic blood pressure $(3.0 \mathrm{mmHg})$, body mass index $\left(0.87 \mathrm{~kg} / \mathrm{m}^{\wedge} 2\right)$, waist circumference $(1.3 \mathrm{~cm})$, body fat percentage $(1.7 \%)$, low-density lipoprotein levels in blood $(0.16 \mathrm{mmol} / \mathrm{L})$, and the risk of myocardial infarction $(\mathrm{OR}=1.50)$, stroke $(O R=1.52)$, any cardiovascular disease $(O R=1.43)$, and all-cause mortality $(O R=1.41)$. Conversely, increasing use of alcohol was associated with reduced levels of triglycerides ($0.059 \mathrm{mmol} / \mathrm{L})$ and $\mathrm{HbA} 1 \mathrm{C}(-0.42 \mathrm{mmol} / \mathrm{mol})$ in the blood, the latter possibly a consequence of a statistically elevated mean corpuscular volume among $A D H 1 B$ Arg47His carriers. Stratifications by sex and smoking revealed a pattern of more harm of alcohol use among men compared to women, but no consistent difference by smoking status. Men had an increased risk of heart failure $(O R=1.76)$, atrial fibrillation $(O R=1.35)$, and type 2 diabetes $(O R=1.31)$ per additional drink/day. Using summary statistics from external datasets in 2-sample analyses for replication, we found causal associations between alcohol and obesity, stroke, ischemic stroke, and type 2 diabetes. Our results are consistent with an overall harmful effect of alcohol on cardiometabolic health at all levels of use and suggest that even moderate alcohol use should not be promoted as a part of a healthy diet and lifestyle.

\section{Introduction}

The relationship between alcohol and cardiovascular disease is important to understand given the high prevalence of alcohol consumption [1, 2]. In decades of epidemiological work, alcohol consumption has shown an inverse or J-shape association with multiple traits related to cardiometabolic health including Type 2 diabetes [3, 4], non-fatal and fatal coronary heart disease [5-7], ischemic stroke [8-10], atrial-fibrillation [11], and congestive heart failure [12].

One interpretation of these relationships has been that moderate drinking is beneficial to cardiometabolic health. A problem with this interpretation is that the relationship is inconsistent with that observed for some known risk factors; for example, alcohol has been directly associated with outcomes such as hypertension irrespective of the degree of intake [13]. A longstanding hypothesis to reconcile these observations stipulates that the negative effects on blood pressure are modest and are surpassed by the positive effects on HDL levels [14, 15] that are either directly affected by alcohol and/or a consequence of an improvement in insulin sensitivity [16]. However, this hypothesis has been challenged in the last decade by multiple randomized control trials of HDL-raising drugs, as well as Mendelian randomization studies that have failed 
to demonstrate the benefits on risk of cardiovascular disease (CVD) of pharmacologically or genetically raised HDL [17-19].

The extent to which observational studies can shed light on the relationship between alcohol and CVD is questionable due to confounding and reverse causality [20]. Alcohol use is related to cultural, socioeconomic, and lifestyle factors which cannot be fully accounted for in observational analyses. Furthermore, several studies have suggested substantial differences in the effects of alcohol on cardiometabolic traits between men and women [3, 4, 11, 12, 16, 21]. Mendelian randomization (MR) facilitates a comparison of groups of subjects that consume more vs. less alcohol that is free of confounding, allowing us to better understand the causal effect of consumption. In this study, we determine the causal relationship between alcohol and cardiovascular risk factors and disease in the UK Biobank by performing an instrumental variable analysis using a genetic variant in a gene $(A D H 1 B)$ that is known to be responsible for the metabolism of alcohol and associated with the amount of alcohol consumed. We attempt to validate findings using summary statistics from external consortial studies for related phenotypes. Within the UK Biobank, we also take advantage of the large numbers to explore strength of associations stratified by sex and smoking status.

\section{Methods}

\section{Study cohort}

The UK Biobank is a prospective study of over 500,000 participants recruited in 2006-2010 [22]. Data collected from the participants included questionnaires, physical measures, sample assays, genotyping, and ongoing longitudinal hospital records. Participants were enrolled at age 40-69. This research has been conducted using the UK Biobank Resource under Application Number 13721. The Research Ethics Committee reference for UK Biobank is 16/NW/0274. The Stanford IRB reviewed the protocol and determined the research did not include human subjects as defined in 45 CFR 46, nor 21 CFR 56.

\section{Outcomes and quantitative traits}

We extracted systolic and diastolic blood pressure, BMI, waist circumference, and body fat percentage from survey data which included physical measurement at the baseline clinic visit. We obtained lipids, blood count variables, and $\mathrm{HbA} 1 \mathrm{C}$ from the biomarkers data. We extracted primary and secondary diagnosis disease outcomes from hospital data for myocardial infarction, stroke (hemorrhagic, ischemic, and any stroke), heart failure, atrial fibrillation, and a composite outcome of all cardiovascular events combined, as well as death from each of these disease outcomes according to the relevant ICD codes (S1.1). We derived type 2 diabetes status from a combination of diabetes-related questions and self-reported medications (S1.2). 


\section{Main exposure and covariates}

Our main exposure variable of interest was self-reported alcohol use by number of drinks per week or month and type of drink obtained from the survey data. Use of all types of alcohol was aggregated into total grams of alcohol intake per year [23], which was then transformed into equivalent daily glasses of wine $(0,>0-1,>1-2,>2-3$, and $>3)$ to facilitate interpretability. Covariates also from survey data included sex, age, region of recruitment, socioeconomic status, ethnicity, smoking status, blood pressure medications, cholesterol-lowering medications, insulin and other diabetes drugs, and fasting status (for biomarkers) (S2).

We used Arg47His (rs1229984) in ADH1B as our genetic instrument for alcohol use. This variant is arguably the strongest and most established genetic predictor of self-reported alcohol use in European populations with a frequency of about 0.5\% (Northern Europe) to 4\% (Southern Europe) $[24,25]$. The variant was directly genotyped using the UK Biobank array and thus no imputation of this variant was necessary.

\section{Statistical analysis}

We characterized the observational relationship between alcohol use and continuous variable risk factors using linear regression for quantitative traits, logistic regression for type 2 diabetes, and Cox proportional hazards regression for cardiovascular events or death. The reference group for all observational analyses was current non-drinkers. For our Cox analyses, we defined the start of follow up as time of enrollment into the UK Biobank study and excluded those with a cardiovascular event prior to the questionnaire to minimize survivor bias. We created two models for each outcome in our observational analysis, one model minimally adjusted for typical epidemiologic covariates (sex, age, region of recruitment, socioeconomic status, ethnicity, and smoking status; for biomarker outcomes, fasting status was also included) and one model additionally adjusted for heart disease risk factors as well as medications that affect those risk factors (BMI and waist circumference, in all models other than those for anthropometric measures; SBP and DBP, in all models other than those for blood pressure; $\mathrm{HbA} 1 \mathrm{C}$ and diabetic medications, in models other than for type 2 diabetes; LDL, HDL, and triglycerides, in all models other than those for lipids; and lipid-lowering, or anti-hypertensive medications).

We included all non-related individuals of European descent (for sample independence and to avoid population stratification) in the UK Biobank for our MR analyses. We grouped heterozygous and homozygous carriers (dominant model). We quantified the strength of the instrument variable using ANOVA and tested the relationship between the instrument variable and alcohol consumption using linear regression. We performed a one-sample MR using the two-stage least squares method with individual level UK Biobank data to estimate the causal effect on traits of consuming one additional drink per day on average. Given possible differences in drinking patterns by sex and smoking status, we also conducted stratified analyses in male, female, current smoker, and never smoker subgroups. We used the BreslowDay test for heterogeneity of odds ratios to test whether outcomes varying substantially between strata were significantly different. For relevant outcomes, we conducted sensitivity analyses in subgroups not taking medications for diabetes, hypertension, and lipids. Lastly, we conducted 
an analysis of hemoglobin, hematocrit, and mean corpuscular volume levels by instrument variable status as an additional check on the potential confounding effects of anemia on our association analyses involving $\mathrm{HbA1C}$. For replication in other datasets, we collected summary statistics for the largest available dataset of European or mostly European ancestry for each outcome (Table S3). We used these summary statistics for a two-sample MR, calculating the ratio of each summary statistic coefficient to the exposure-instrument variable coefficient from the UK Biobank. Analyses were done in R 3.6.3. Results were validated with the MendelianRandomization package.

\section{Results}

UK Biobank participant characteristics are described in Table 1 and S5.1. At recruitment, 92\% of participants consumed alcohol. About half of participants reported drinking alcohol 1-4 times per week, and an additional one fifth of participants reported drinking daily. On average, participants reported drinking $7.7( \pm 9.4)$ glasses per week.

Exclusion of those with prior CVD $(n=21,386)$ yielded a dataset of 481,150 (Table 1). For our observational analysis (Figure S4.1-4S.2, Table S4.3-S4.6), increased alcohol use was directly related to higher systolic and diastolic blood pressure, total cholesterol, HDL, and atrial fibrillation in the fully-adjusted model. We observed a J-shape association (compared with no drinking, lower coefficient/odds ratio/hazard ratio with moderate drinking, but higher with heavy drinking) with BMI, waist circumference, body fat percentage, stroke (total, ischemic, and hemorrhagic), and all-cause death. Triglycerides, type 2 diabetes, myocardial infarction, heart failure and total cardiovascular disease also had a J-shape association, but with lower betas/odds ratio/hazard ratio at all drinking levels compared with non-drinkers. Alcohol was inversely associated with $\mathrm{HbA1C}$. No pattern was observed between alcohol and LDL.

The Arg47His $A D H 1 B$ variant was found in $4.4 \%$ of individuals in the UK Biobank, with only 188 homozygous for the variant. Our MR analysis $(n=337,484)$ showed that those with the wildtype consumed 2.1 drinks/week more than carriers of the Arg47His variant in $A D H 1 B(7,127 \mathrm{~g} /$ year or 8.2 glasses/week for wildtype vs 5,276 g/year or 6.1 glasses/week for carriers; $F=718$ ) (Table 2). The two-stage least squares analysis showed that alcohol intake equivalent to one additional glass of wine per day was causally associated with higher systolic blood pressure $(2.99 \mathrm{mmHg}), \mathrm{BMI}\left(0.87 \mathrm{~kg} / \mathrm{m}^{\wedge} 2\right)$, waist circumference $(1.34 \mathrm{~cm})$, body fat percentage $(1.68 \%)$, cholesterol $(0.160 \mathrm{mmol} / \mathrm{L})$, LDL $(0.155 \mathrm{mmol} / \mathrm{L})$. Triglycerides $(-0.059 \mathrm{mmol} / \mathrm{L})$ and HbA1C ($0.420 \mathrm{mmol} / \mathrm{mol}$ ) were significantly lower while diastolic blood pressure and HDL showed no difference. For disease events, one additional drink/week corresponded to higher risk of MI (OR $=1.50)$, all stroke $(O R=1.52)$, any cardiovascular disease $(O R=1.43)$, and all-cause death $(\mathrm{OR}=1.41)$, while other disease events showed no change.

Drinking varied by sex (men: 11.1 glasses/week vs. women: 5.4 glasses/week) and by smoking status (current smokers: 9.8 glasses/week vs. never-smokers: 6.5 glasses/week) in stratified analyses (Table 2). One additional drink per day corresponded to higher systolic blood 
pressure, BMI, waist circumference, body fat percentage, and LDL in all groups. Men additionally had higher risk of heart failure $(O R=1.76)$, atrial fibrillation $(O R=1.35)$, and type 2 diabetes $(O R=1.31)$ with one additional drink per day, while there was no difference in risk for these diseases in women. Women did not have any increase in myocardial infarction with alcohol use. We measured statistical evidence for heterogeneity of the OR between men and women for myocardial infarction $(p=0.070)$, heart failure $(p=0.048)$, atrial fibrillation $(p=0.041)$, type 2 diabetes $(p=0.068)$, all CVD $(p=0.013)$, and all-cause death $(p=0.015)$.

Sensitivity analyses in subgroups not taking medications for diabetes, hypertension, and lipids showed negligible differences in results for $\mathrm{HbA} 1 \mathrm{C}$, systolic/diastolic blood pressure, and LDL/triglycerides, respectively (S5.2). Analysis of blood count data by instrument variable showed that those with the wildtype, who drink more, had a lower hemoglobin $(-0.02 \mathrm{~g} / \mathrm{dL}$, $\mathrm{p}=0.0018)$ and hematocrit $(-0.09 \%, \mathrm{p}=0.0024)$, and a higher mean corpuscular volume $(+0.27$ $\left.\mathrm{fL}, \mathrm{p}=2.4 \times 10^{-13}\right)($ Table S5.3).

In summary statistics from external datasets, alcohol was predictive of stroke and ischemic stroke (MEGASTROKE), type 2 diabetes (DIAMANTE), BMI (GIANT-UK Biobank metaanalysis), and waist circumference (EXTEND) (Figure 1).

\section{Discussion}

Our principal analysis within the UK Biobank suggests that alcohol is causally associated not only with a range of adverse cardiovascular related outcomes such as myocardial infarction, stroke, and all-cause death, but also multiple traditional risk factors for these outcomes that likely mediate these observed effects including hypertension (systolic blood pressure), obesity (waist circumference, body fat percentage), and atherogenic dyslipidemia (cholesterol, LDL). Our findings in the UK Biobank were further supported by analyses involving external datasets for a subset of these outcomes including obesity (BMI, waist circumference), stroke, and Type 2 diabetes. Our MR analyses gave discrepant results when compared to the analogous observational analysis for these phenotypes, which suggests the presence of residual confounding from unmeasured factors in observational analysis.

Two findings in our analyses are inconsistent with the hypothesis of a causal negative effect on cardiometabolic outcomes mediated through risk factors. First, we found alcohol to be causally associated with a lower level of triglycerides in the UK Biobank, which would be expected to reduce the risk of atherosclerosis related outcomes. We note this finding is contrary to what has been observed experimentally [26]; but consistent with other MR studies [27-29]. Although multiple MR studies suggest triglycerides are causally associated with CVD, clinical trials of triglyceride-lowering agents have not consistently supported this relationship leading to the conclusion that how triglycerides are lowered plays an important role in whether that lowering translates to cardiovascular benefit. Second, we found alcohol to be inversely associated with $\mathrm{HbA} 1 \mathrm{C}$ which would be expected to reduce the risk of Type 2 diabetes. We suspect this counterintuitive association observed may be a technical artifact driven by the presence of a 
mild (possibly nutritional) macrocytosis we observed among participants not carrying the minor allele at rs 1229984 that biases HgA1C levels downwards without truly altering the risk of diabetes[30, 31].

Our stratified analyses suggest that alcohol is more harmful for men than for women for nearly all outcomes. We observed the largest differences in the point estimates of the harmful effect for heart-related outcomes (myocardial infarction, heart failure, and atrial fibrillation) with a smaller difference observed for type 2 diabetes. For most outcomes, the point estimate of effect of alcohol for women was near 1 . Tests for heterogeneity of odds ratios for outcomes which appeared to differ between men and women were not definitive as to whether a true difference exists but strongly suggestive. Larger samples sizes are needed to more reliably document a statistically significant modification of effect of alcohol between men and women. If confirmed, these findings would suggest that causal negative effects of alcohol may only begin to express themselves at a higher consumption level despite differences in body surface area and rate of metabolism between females and males. We did not observe the same trend between our smoking subgroup analysis where the effect of drinking did not differ substantially between smokers and non-smokers for most outcomes.

Our findings are largely consistent with the existing literature of MR studies of alcohol and cardiovascular risk factors and outcomes which have found alcohol to be harmful for CVD related outcomes and most cardiometabolic risk factors [27-29, 32, 33]. For example, the first large MR study of risk factors and outcomes using data gathered from over 56 cohort studies of individuals of European ancestry and the same genetic instrument in $A D H 1 B$ found moderate alcohol use to be associated with higher systolic blood pressure, waist circumference, BMI, LDL, and risk of coronary heart disease [28]. Another smaller MR study in Danes also found a direct association with a higher BMI [27]. A study of the China Kadoorie biobank $(>500,000)$ used a combination of instruments in both $A L D H 2$ and $A D H 1 B$ found alcohol to be positively associated with increasing systolic blood pressure, HDL, ischemic stroke, and intracerebral hemorrhage, but no effect was found for myocardial infarction [32]. Another recent study of alcohol and CVD outcomes in the UK Biobank using a multi-SNP instrument variable found an increase in blood pressure, stroke, and peripheral artery disease [29]. The inverse association of alcohol with triglycerides that we observed has also been shown in several other MR studies[27-29]. Diabetes has previously been found to have no association with alcohol in an MR meta-analysis (>14,000 cases) as instrumented by the same variant we used [28]. However, another study in a Chinese population using the $A L D H 2$ rs671 variant, which has a more profound effect on alcohol intake, found a higher risk of diabetes with increasing alcohol [33]. Unique contributions of our study include the identification of the harmful effects of alcohol on body fat percentage and all-cause death. Our study also adds to the existing literature by showing sex-stratified differences which merit further investigation.

Major strengths of our study include the use of a single SNP as a genetic instrument to predict causality of alcohol consumption combined with a large sample size. Using a single instrument within an alcohol metabolizing gene that is strongly associated with the exposure maximizes the probability that the all assumptions of an MR study have been met and the results are 
accurately reflecting a relationship that is free from any residual confounding [34]. A potential weakness may be the generalizability of our study given the well-established healthy cohort effect observed for the UK Biobank [35], although the healthy cohort may have helped by minimizing the inclusion of subjects with alcohol use disorder and/or moderate but still high-risk use of alcohol (e.g. binge drinkers). Our results are also limited to UK residents and therefore may vary somewhat in other populations although MR studies to date in other populations including Chinese are largely consistent with our findings[27, 28, 32, 33]. More research is needed on the determination of the causal effects of alcohol consumption in race/ethnic groups other than Europeans and East Asians to determine if effects observed to date generalize to all major race/ethnic groups.

Proposed mechanisms for the negative effect of alcohol on cardiometabolic disease include a pathway via raised blood pressure [36] and atherogenic lipids [37] as well as increased adiposity and subsequent risk of Type2 diabetes, consistent with our MR findings and those of others. Raised HDL has been proposed as a protective factor but our MR results do not support that such elevations are directly related to alcohol among a population of predominantly moderate alcohol users. The same relationship with HDL has been observed in other MR studies[28, 29, 33]. Additionally, multiple lines of evidence now suggest that HDL levels are not causally associated with heart disease $[17,18]$ but instead serve as a marker of a variety of factors that may or may not affect the risk of CVD. In this context, one can speculate that physical activity raises HDL in a health-promoting way [38], while alcohol consumption does not. Further harm of alcohol for stroke could come from alcohol induced thrombocytopenia (hemorrhagic stroke) and reduced fibrinolysis (ischemic stroke) with alcohol use [39].

In conclusion, our analysis adds to the mounting evidence using MR that alcohol use does not improve cardiovascular health even in moderate amounts and likely worsens it when all other factors are considered. Given this evidence and the fact that alcohol is implicated in a number of public health concerns not directly related to cardiometabolic health, including addictive disorders, accidents, suicides, liver disease, and various types of cancers (e.g. esophageal, gastrointestinal, head and neck) [40], we believe it is time to reconsider current public health recommendations in the US and other countries which suggest that up to two drinks/day for men and one drink/day for women is not harmful and possibly beneficial to cardiovascular health [41]. This reconsideration is also supported by a more recent observational study that considered the full spectrum of alcohol related health consequences across the entire age spectrum and concluded that the level of consumption that minimizes health loss is zero [40]. Properly conducted randomized control trials [42] may one day more reliably inform us on this matter but, until that time comes, Mendelian randomization analyses provides an acceptable alternative to help inform health policy in this respect. 


\section{Tables and figures}

\section{Table 1}

Summary of characteristics of UK Biobank participants in datasets used for analyses, $\mathrm{n}(\%)$ or mean(standard deviation)

\begin{tabular}{|c|c|c|c|}
\hline Variable & Total dataset & $\begin{array}{l}\text { Observational } \\
\text { analysis }\end{array}$ & $\begin{array}{l}\text { Mendelian } \\
\text { randomization }\end{array}$ \\
\hline $\mathrm{n}$ & 502536 & 481150 & 337484 \\
\hline \multicolumn{4}{|l|}{ Sex } \\
\hline Female & 273402 (54.4) & 267459 (55.6) & 181236 (53.7) \\
\hline Male & $229134(45.6)$ & 213691 (44.4) & $156248(46.3)$ \\
\hline Age (years) & $67.3(8.1)$ & $67(8.1)$ & $67.6(8)$ \\
\hline \multicolumn{4}{|l|}{ Region } \\
\hline England & $445883(88.7)$ & 427194 (88.8) & 297645 (88.2) \\
\hline Wales & 20808 (4.1) & $19936(4.1)$ & $14824(4.4)$ \\
\hline Scotland & 35845 (7.1) & $34020(7.1)$ & $25015(7.4)$ \\
\hline Townsend index & $-1.3(3.1)$ & $-1.3(3.1)$ & $-1.6(2.9)$ \\
\hline \multicolumn{4}{|l|}{ Ethnic group } \\
\hline White & 472725 (94.1) & 452534 (94.1) & $337484(100)$ \\
\hline Asian or Asian British & $11456(2.3)$ & $10847(2.3)$ & $0(0)$ \\
\hline Black or Black British & $8061(1.6)$ & $7863(1.6)$ & $0(0)$ \\
\hline Mixed or other & $7517(1.5)$ & $7279(1.5)$ & $0(0)$ \\
\hline Don't know/refused & $2777(0.6)$ & $2627(0.5)$ & $0(0)$ \\
\hline \multicolumn{4}{|l|}{ Smoking status } \\
\hline Never-smoker & $273537(54.4)$ & 265259 (55.1) & $183826(54.5)$ \\
\hline Current smoker & $52979(10.5)$ & $50453(10.5)$ & $33977(10.1)$ \\
\hline Former smoker & $173070(34.4)$ & 162687 (33.8) & 118505 (35.1) \\
\hline No response & $2950(0.6)$ & $2751(0.6)$ & $1176(0.3)$ \\
\hline Drinking status & & & \\
\hline
\end{tabular}




\begin{tabular}{|l|l|l|l|}
\hline \multicolumn{1}{|c|}{ Never-drinker } & $22388(4.5)$ & $21234(4.4)$ & $10392(3.1)$ \\
\hline Current drinker & $460386(91.6)$ & $441728(91.8)$ & $315257(93.4)$ \\
\hline Former drinker & $18108(3.6)$ & $16631(3.5)$ & $11543(3.4)$ \\
\hline No response & $1654(0.3)$ & $1557(0.3)$ & $292(0.1)$ \\
\hline Drinking frequency & & & \\
\hline Daily or almost daily & $101774(20.3)$ & $97438(20.3)$ & $72270(21.4)$ \\
\hline Three or four times a week & $115445(23)$ & $111123(23.1)$ & $81462(24.1)$ \\
\hline Once or twice a week & $129297(25.7)$ & $124157(25.8)$ & $88747(26.3)$ \\
\hline One to three times a month & $55858(11.1)$ & $53724(11.2)$ & $37367(11.1)$ \\
\hline Special occasions only & $58012(11.5)$ & $55286(11.5)$ & $35411(10.5)$ \\
\hline Never & $40648(8.1)$ & $38009(7.9)$ & $21991(6.5)$ \\
\hline No response & $1502(0.3)$ & $1413(0.3)$ & $236(0.1)$ \\
\hline $\begin{array}{l}\text { Alcohol (weekly equivalent glasses } \\
\text { of wine) }\end{array}$ & $7.7(9.4)$ & $7.7(9.4)$ & $8.1(9.5)$ \\
\hline Systolic blood pressure (mmHg) & $139.7(19.7)$ & $139.7(19.7)$ & $140.2(19.7)$ \\
\hline Diastolic blood pressure (mmHg) & $82.2(10.7)$ & $82.3(10.7)$ & $82.2(10.7)$ \\
\hline Body mass index (kg/m^2) & $27.4(4.8)$ & $27.4(4.8)$ & $27.4(4.7)$ \\
\hline Waist circumference (cm) & $90.3(13.5)$ & $90(13.4)$ & $90.3(13.5)$ \\
\hline Body fat percentage & $31.5(8.5)$ & $31.5(8.6)$ & $31.4(8.5)$ \\
\hline Cholesterol (mmol/L) & $5.7(1.1)$ & $5.7(1.1)$ & $5.7(1.1)$ \\
\hline LDL (mmol/L) & $3.6(0.9)$ & $3.6(0.9)$ & $3.6(0.9)$ \\
\hline HDL (mmol/L) & $1.4(0.4)$ & $1.5(0.4)$ & $1.5(0.4)$ \\
\hline Triglycerides (mmol/L) & $1.7(1)$ & $1.7(1)$ & $1.8(1)$ \\
\hline HbA1c (mmol/mol) & $36.1(6.8)$ & $36(6.5)$ & $36(6.5)$ \\
\hline Glucose (mmol/L) & $5.1(1.2)$ & $5.1(1.2)$ & $5.1(1.2)$ \\
\hline Type 2 diabetes & $25217(5)$ & $22083(4.6)$ & $15493(4.6)$ \\
\hline Coronary heart disease & $24047(4.8)$ & $11297(2.3)$ & $16102(4.8)$ \\
\hline All stroke & $11785(2.3)$ & $6857(1.4)$ & $8044(2.4)$ \\
\hline Ischemic stroke & $5081(1)$ & $3217(0.7)$ & $3427(1)$ \\
\hline Hemorrhagic stroke & $2814(0.6)$ & $1608(0.3)$ & $1877(0.6)$ \\
\hline Heart failure & $8956(1.8)$ & $5128(1.1)$ & $5921(1.8)$ \\
\hline
\end{tabular}




\begin{tabular}{|l|l|l|l|}
\hline Atrial fibrillation & $22197(4.4)$ & $14292(3)$ & $15483(4.6)$ \\
\hline Any cardiovascular disease & $52219(10.4)$ & $30833(6.4)$ & $35499(10.5)$ \\
\hline All-cause death & $20284(4)$ & $17635(3.7)$ & $13700(4.1)$ \\
\hline ADH1B status & & & \\
\hline Wildtype & $458807(91.3)$ & $439084(91.3)$ & $322519(95.6)$ \\
\hline Carrier & $26534(5.3)$ & $25593(5.3)$ & $14777(4.4)$ \\
\hline Homozygous minor allele & $1979(0.4)$ & $1928(0.4)$ & $188(0.1)$ \\
\hline
\end{tabular}

\section{Table 2}

Mean alcohol consumption in equivalent glasses of wine per week by group and ADH1B status.

\begin{tabular}{|c|c|c|c|}
\hline Group & $\begin{array}{l}\text { Wildtype, } \\
\text { glasses/week }\end{array}$ & $\begin{array}{l}\text { Variant, } \\
\text { glasses/week }\end{array}$ & $\begin{array}{l}\text { Increase for wild type, } \\
\text { glasses/week }\end{array}$ \\
\hline all & 8.2 & 6.1 & 2.1 \\
\hline male & 11.2 & 8.4 & 2.8 \\
\hline female & 5.5 & 3.9 & 1.6 \\
\hline current smoker & 11.1 & 7.6 & 3.5 \\
\hline never-smoker & 6.5 & 4.6 & 1.9 \\
\hline
\end{tabular}




\section{Figure 1}

See separate PDFs

Caption title: Results from Mendelian randomization of outcome variables in UK Biobank and external datasets

Caption: Significant results shown in black with circles; non-significant results shown in gray with squares.

Figure 1a: Mendelian randomization results for blood pressure and anthropometric measures Figure $1 \mathrm{~b}$ : Mendelian randomization results for biochemistry variables

Figure 1c: Mendelian randomization results for disease outcomes and death

\section{Figure 2}

See separate PDFs

Caption title: Results from Mendelian randomization of outcome variables in UK Biobank stratified by sex and smoking status

Caption: Significant results shown in black with circles; non-significant results shown in gray with squares.

Figure 2a: Stratified Mendelian randomization results for blood pressure and anthropometric measures

Figure 2b: Stratified Mendelian randomization results for biochemistry variables

Figure 2c: Stratified Mendelian randomization results for disease outcomes and death 


\section{Supplement}

\section{Supplemental methods detail}

\section{S1. Data transformations}

\section{S1.1 Disease events}

Disease events were defined according to each of the following ICD codes and extracted from hospital data (using both primary and secondary diagnoses).

\begin{tabular}{|c|c|c|c|}
\hline Event & ICD-9 & ICD-10 & OPCS-4 \\
\hline $\begin{array}{l}\text { Myocardial } \\
\text { infarction }\end{array}$ & $410^{*}, 411^{*}$ & $120.0,121^{*}, 122^{*}$ & $\begin{array}{l}\mathrm{K} 40^{*}, \mathrm{~K} 41^{*}, \mathrm{~K} 42^{*}, \mathrm{~K} 43^{*}, \mathrm{~K} 44^{*}, \\
\mathrm{~K}^{*} 5^{*}, \mathrm{~K} 46^{*}, \mathrm{~K}^{*}, \mathrm{~K} 50^{*}, \mathrm{~K} 75^{*}\end{array}$ \\
\hline All stroke & $\begin{array}{l}430^{*}, 431^{*}, 432^{*} \\
433^{\star}, 434^{*}, 435^{\star}, 436^{*}\end{array}$ & $\begin{array}{l}160^{*}, 161^{*}, 162^{*} \\
163^{*}, \mathrm{G} 45^{*}, 164^{*}\end{array}$ & $n / a$ \\
\hline Ischemic stroke & $433^{*}, 434^{*}$ & $163^{*}$ & $n / a$ \\
\hline $\begin{array}{l}\text { Hemorrhagic } \\
\text { stroke }\end{array}$ & $430^{*}, 431^{*}, 432^{*}$ & $160^{*}, 161^{*}, 162^{*}$ & $n / a$ \\
\hline Heart failure & $428^{*}$ & $150^{*}$ & $n / a$ \\
\hline Atrial fibrillation & $427.3^{*}$ & $148^{*}$ & $\mathrm{~K} 52.1, \mathrm{~K} 62.2, \mathrm{~K} 62.3, \mathrm{~K} 62.4$ \\
\hline
\end{tabular}

* Including all subcategories

\section{S1.2 Diabetes}

Diabetes was defined using self-reported diabetes (question \# 1221, 1222, 1223), self-reported medical conditions (question \# 20002), self-reported medications (question \# 20003), HbA1C results (question \# 30750), age of diagnosis (question \# 2976), started insulin within one year of diagnosis (question \# 2986), diabetes diagnosed by a doctor (question \# 2443), diabetes gestational only (question \# 4041).

We flagged individuals who had suspected Type 1 diabetes. We considered individuals to have Type 2 diabetes if they were not flagged for Type 1, and any of the following was true:

- HbA1C exceeded threshold of $48 \mathrm{mmol} / \mathrm{mol}$

- Type 2 diabetes was in their self-reported medical conditions

- Diabetes medications were self-reported

- Diabetes had been diagnosed by a doctor but was not gestational only

We flagged individuals for suspected type 1 diabetes if:

- Type 1 diabetes was in reported conditions, OR

- Diabetes was diagnosed before age 35, OR

- Insulin began within a year of diagnosis. 


\section{S2. Observational analysis}

In the partially-adjusted model, we used the Townsend index to adjust for socioeconomic status. Ethnicity was grouped by the highest tree-structure group of the 21000 variable. Region was encoded as England, Scotland, or Wales. Antihypertensive and lipid-lowering medications were extracted from variables 6153 and 6177. Diabetes medications came from variables 6153 , 6177 , and 20003. Sex, age, and smoking status also came from survey data. Fasting time (variable 74) was also used in all biomarker outcome models.

Strikethrough text indicates a variable was not included in the fully-adjusted model.

\begin{tabular}{|l|l|}
\hline Outcome & Fully adjusted includes all the partially adjusted plus: \\
\hline $\begin{array}{l}\text { BMI, waist circumference, body } \\
\text { fat percentage }\end{array}$ & $\begin{array}{l}\text { HbA1c, diabetes medications, BMI, waist circumference, } \\
\text { SBP, DBP, anti-hypertensive, LDL, HDL, triglycerides, } \\
\text { lipid-lowering }\end{array}$ \\
\hline SBP and DBP & $\begin{array}{l}\text { HbA1c, diabetes medications, BMI, waist circumference, } \\
\text { SBP, DBP, anti-hypertensive, LDL, HDL, triglycerides, } \\
\text { lipid-lowering }\end{array}$ \\
\hline Type 2 diabetes & $\begin{array}{l}\text { HbA1c, diabetes medications, BMI, waist circumference, } \\
\text { SBP, DBP, anti-hypertensive, LDL, HDL, triglycerides, } \\
\text { lipid-lowering }\end{array}$ \\
\hline $\begin{array}{l}\text { Cholesterol, LDL, HDL, } \\
\text { triglycerides }\end{array}$ & $\begin{array}{l}\text { HbA1c, diabetes medications, BMI, waist circumference, } \\
\text { SBP, DBP, anti-hypertensive, LDL, HDL, triglycerides, } \\
\text { lipid-lowering }\end{array}$ \\
\hline HBA1C & $\begin{array}{l}\text { HbA1c, diabetes medications, BMI, waist circumference, } \\
\text { SBP, DBP, anti-hypertensive, LDL, HDL, triglycerides, } \\
\text { lipid-lowering }\end{array}$ \\
\hline $\begin{array}{l}\text { Heart disease events (CHD, } \\
\text { stroke, etc) }\end{array}$ & $\begin{array}{l}\text { HbA1c, diabetes medications, BMI, waist circumference, } \\
\text { SBP, DBP, anti-hypertensive, LDL, HDL, triglycerides, } \\
\text { lipid-lowering }\end{array}$ \\
\hline
\end{tabular}

\section{S3. Mendelian randomization analysis}

Where possible, we utilized the Cardiovascular Disease, Cerebrovascular Disease, and Type 2 Diabetes Knowledge Portals.

Table S3: Data sources for Mendelian randomization. * indicates the source also includes UK Biobank data.

CVDKP = Cardiovascular disease knowledge portal [43],

http://www.broadcvdi.org/home/portalHome

CDKP = Cerebrovascular disease knowledge portal [44], http://cerebrovascularportal.org/

T2DKP = Type 2 diabetes knowledge portal [45], http://www.type2diabetesgenetics.org/ 


\begin{tabular}{|c|c|c|c|c|}
\hline Name & $\begin{array}{l}\text { Extracted } \\
\text { summary } \\
\text { statistics for } \\
\text { phenotypes }\end{array}$ & $\begin{array}{l}\text { Population } \\
\text { ancestry }\end{array}$ & $\mathbf{n}$ & From \\
\hline $\begin{array}{l}\text { CARDIoGRAMplusC4D } \\
\text { with } 1000 \text { genomes GWAS } \\
\text { meta-analysis [46] }\end{array}$ & $\begin{array}{l}\text { Myocardial } \\
\text { infarction }\end{array}$ & Mixed & 184,305 & $\begin{array}{l}\text { http://www.cardio } \\
\text { gramplusc4d.org/ } \\
\text { data-downloads/ }\end{array}$ \\
\hline MEGASTROKE [47] & $\begin{array}{l}\text { All stroke, } \\
\text { Ischemic stroke }\end{array}$ & Mixed & 521,612 & CDKP \\
\hline $\begin{array}{l}\text { HERMES Heart Failure } \\
\text { GWAS }^{*}[48]\end{array}$ & Heart failure & European & 972,032 & CVDKP \\
\hline 2018 AF HRC GWAS [49] & Atrial fibrillation & Mixed & 588,190 & CVDKP \\
\hline $\begin{array}{l}\text { DIAMANTE T2D GWAS* } \\
\text { [50] }\end{array}$ & Type 2 diabetes & European & 898,130 & T2DKP \\
\hline $\begin{array}{l}\text { FinnMetSeq exome } \\
\text { sequence analysis [51] }\end{array}$ & $\begin{array}{l}\text { Systolic blood } \\
\text { pressure, diastolic } \\
\text { blood pressure, } \\
\text { body fat } \\
\text { percentage }\end{array}$ & European & 19,291 & T2DKP \\
\hline MAGIC GWAS [52] & $\mathrm{HbA} 1 \mathrm{C}$ & European & 5,318 & T2DKP \\
\hline $\begin{array}{l}\text { GIANT } 2018 \text { BMI, Height } \\
\text { exome chip analysis [53] }\end{array}$ & BMI & European & 449,889 & $\begin{array}{l}\text { https://portals.bro } \\
\text { adinstitute.org/coll } \\
\text { aboration/giant/in } \\
\text { dex.php/GIANT_c } \\
\text { onsortium_data_fi } \\
\text { les }\end{array}$ \\
\hline $\begin{array}{l}\text { GIANT-UK Biobank } \\
\text { GWAS Meta-analysis* [54] }\end{array}$ & BMI & European & 694,649 & T2DKP \\
\hline EXTEND GWAS [55] & $\begin{array}{l}\text { Waist } \\
\text { circumference }\end{array}$ & European & 7,159 & T2DKP \\
\hline $\begin{array}{l}\text { Body fat percentage } \\
\text { GWAS [56] }\end{array}$ & $\begin{array}{l}\text { Body fat } \\
\text { percentage }\end{array}$ & $\begin{array}{l}\text { Mixed } \\
(89,267 \\
\text { European) }\end{array}$ & 100,716 & T2DKP \\
\hline $\begin{array}{l}\text { GLGC exome chip analysis } \\
\text { [57] }\end{array}$ & $\begin{array}{l}\text { Total cholesterol, } \\
\text { LDL, HDL, } \\
\text { triglycerides }\end{array}$ & $\begin{array}{l}\text { Mixed } \\
(273,050 \\
\text { European })\end{array}$ & $\sim 300,000$ & $\begin{array}{l}\text { https://my.locuszo } \\
\text { om.org/gwas/919 } \\
\text { 709/ }\end{array}$ \\
\hline
\end{tabular}




\section{Supplemental results}

\section{S4. Observational analysis results}

All results are compared to a reference of no alcohol consumption

SBP: Systolic blood pressure $(\mathrm{mmHg})$

DBP: Diastolic blood pressure $(\mathrm{mmHg})$

BMI: Body mass index $\left(\mathrm{kg} / \mathrm{m}^{\wedge} 2\right)$

WAIST: Waist circumference $(\mathrm{cm})$

BFP: Body fat percentage

CHOL: Cholesterol (mmol/L)

LDL: Low-density lipoprotein ( $\mathrm{mmol} / \mathrm{L})$

HDL: High-density lipoprotein ( $\mathrm{mmol} / \mathrm{L}$ )

TG: Triglycerides (mmol/L)

HBA1C: Glycated hemoglobin ( $\mathrm{mmol} / \mathrm{mol}$ )

T2D: type 2 diabetes

MI: myocardial infarction

ALLSTROKE: all types of stroke

ISTROKE: ischemic stroke

HSTROKE: hemorrhagic stroke

$\mathrm{HF}$ : heart failure

AFIB: atrial fibrillation

CVD: any cardiovascular disease (MI, ALLSTROKE, ISTROKE, HSTROKE, HF, AFIB)

Death: all-cause death

Figure S4.1: Observational analysis results for effect size for given drinking category (units listed with abbreviations) for fully adjusted model.

Figure S4.2: Observational analysis results for hazard ratio (event outcomes) or odds ratio (type 2 diabetes) for fully adjusted model. 
S4.3 Betas and confidence intervals for continuous measures, basic model. Reference: no alcohol consumption.

\begin{tabular}{|c|c|c|c|c|c|c|c|c|c|c|}
\hline \begin{tabular}{|l|} 
glasses \\
/day
\end{tabular} & SBP & DBP & BMI & WAIST & BFP & CHOL & LDL & HDL & TG & HBA1C \\
\hline$>0-1$ & $\begin{array}{l}0.22 \\
(0.07,0.36)\end{array}$ & $\begin{array}{l}-0.010 \\
(-0.09,0.07)\end{array}$ & $\begin{array}{l}-1.17 \\
(-1.21,-1.14)\end{array}$ & $\begin{array}{l}-2.66 \\
(-2.74,-2.57)\end{array}$ & $\begin{array}{l}-1.11 \\
(-1.15,-1.06)\end{array}$ & $\begin{array}{l}0.11 \\
(0.10,0.12)\end{array}$ & $\begin{array}{l}0.03 \\
(0.02,0.04)\end{array}$ & $\begin{array}{l}0.11 \\
(0.10,0.11)\end{array}$ & $\begin{array}{l}-0.14 \\
(-0.14,-0.13)\end{array}$ & $\begin{array}{l}-0.99 \\
(-1.04,-0.94)\end{array}$ \\
\hline$>1-2$ & $\begin{array}{l}1.02 \\
(0.86,1.18)\end{array}$ & $\begin{array}{l}0.72 \\
(0.62,0.81)\end{array}$ & $\begin{array}{l}-1.40 \\
(-1.44,-1.36)\end{array}$ & $\begin{array}{l}-3.03 \\
(-3.13,-2.93)\end{array}$ & $\begin{array}{l}-1.31 \\
(-1.36,-1.25)\end{array}$ & $\begin{array}{l}0.19 \\
(0.18,0.20)\end{array}$ & $\begin{array}{l}0.03 \\
(0.02,0.03)\end{array}$ & $\begin{array}{l}0.20 \\
(0.20,0.21)\end{array}$ & $\begin{array}{l}-0.19 \\
(-0.20,-0.18)\end{array}$ & $\begin{array}{l}-1.60 \\
(-1.66,-1.55)\end{array}$ \\
\hline$>2-3$ & $\begin{array}{l}3.13 \\
(2.92,3.34)\end{array}$ & $\begin{array}{l}2.06 \\
(1.94,2.18)\end{array}$ & $\begin{array}{l}-1.07 \\
(-1.12,-1.02)\end{array}$ & $\begin{array}{l}-2.06 \\
(-2.19,-1.93)\end{array}$ & $\begin{array}{l}-0.79 \\
(-0.86,-0.72)\end{array}$ & $\begin{array}{l}0.28 \\
(0.27,0.29)\end{array}$ & $\begin{array}{l}0.05 \\
(0.04,0.06)\end{array}$ & $\begin{array}{l}0.26 \\
(0.26,0.27)\end{array}$ & $\begin{array}{l}-0.16 \\
(-0.17,-0.15)\end{array}$ & $\begin{array}{l}-1.82 \\
(-1.89,-1.74)\end{array}$ \\
\hline$>3$ & $\begin{array}{l}6.28 \\
(6.05,6.51)\end{array}$ & $\begin{array}{l}3.85 \\
(3.72,3.98)\end{array}$ & $\begin{array}{l}-0.69 \\
(-0.74,-0.63)\end{array}$ & $\begin{array}{l}-0.74 \\
(-0.88,-0.59)\end{array}$ & $\begin{array}{l}-0.18 \\
(-0.25,-0.10)\end{array}$ & $\begin{array}{l}0.40 \\
(0.39,0.41)\end{array}$ & $\begin{array}{l}0.07 \\
(0.06,0.08)\end{array}$ & $\begin{array}{l}0.34 \\
(0.34,0.35)\end{array}$ & $\begin{array}{l}-0.08 \\
(-0.09,-0.06)\end{array}$ & $\begin{array}{l}-1.86 \\
(-1.94,-1.78)\end{array}$ \\
\hline
\end{tabular}

S4.4 Betas and confidence intervals for continuous measures, fully-adjusted model. Reference: no alcohol consumption.

\begin{tabular}{|c|c|c|c|c|c|c|c|c|c|c|}
\hline \begin{tabular}{|l|} 
glasses \\
/day
\end{tabular} & SBP & DBP & BMI & WAIST & BFP & CHOL & LDL & HDL & TG & HBA1C \\
\hline$>0-1$ & $\begin{array}{l}0.72 \\
(0.56,0.87)\end{array}$ & $\begin{array}{l}0.48 \\
(0.39,0.56)\end{array}$ & $\begin{array}{l}-0.54 \\
(-0.57,-0.50)\end{array}$ & $\begin{array}{l}-0.97 \\
(-1.06,-0.88)\end{array}$ & $\begin{array}{l}-0.35 \\
(-0.39,-0.30)\end{array}$ & $\begin{array}{l}0.07 \\
(0.06,0.08)\end{array}$ & $\begin{array}{l}0.01 \\
(0.00,0.02)\end{array}$ & $\begin{array}{l}0.08 \\
(0.07,0.08)\end{array}$ & $\begin{array}{l}-0.07 \\
(-0.08,-0.06)\end{array}$ & $\begin{array}{l}-0.34 \\
(-0.38,-0.29)\end{array}$ \\
\hline$>1-2$ & $\begin{array}{l}1.37 \\
(1.19,1.55)\end{array}$ & $\begin{array}{l}1.21 \\
(1.11,1.31)\end{array}$ & $\begin{array}{l}-0.39 \\
(-0.43,-0.35)\end{array}$ & $\begin{array}{l}-0.32 \\
(-0.43,-0.22)\end{array}$ & $\begin{array}{l}-0.10 \\
(-0.15,-0.04)\end{array}$ & $\begin{array}{l}0.13 \\
(0.12,0.14)\end{array}$ & $\begin{array}{l}0.00 \\
(-0.01,0.00)\end{array}$ & $\begin{array}{l}0.16 \\
(0.16,0.17)\end{array}$ & $\begin{array}{l}-0.11 \\
(-0.12,-0.10)\end{array}$ & $\begin{array}{l}-0.70 \\
(-0.75,-0.65)\end{array}$ \\
\hline$>2-3$ & $\begin{array}{l}2.91 \\
(2.67,3.14)\end{array}$ & $\begin{array}{l}2.17 \\
(2.04,2.30)\end{array}$ & $\begin{array}{l}0.00 \\
(-0.06,0.05)\end{array}$ & $\begin{array}{l}0.87 \\
(0.74,1.00)\end{array}$ & $\begin{array}{l}0.49 \\
(0.42,0.57)\end{array}$ & $\begin{array}{l}0.21 \\
(0.20,0.22)\end{array}$ & $\begin{array}{l}0.01 \\
(0.00,0.01)\end{array}$ & $\begin{array}{l}0.23 \\
(0.23,0.24)\end{array}$ & $\begin{array}{l}-0.11 \\
(-0.12,-0.10)\end{array}$ & $\begin{array}{l}-0.91 \\
(-0.98,-0.85)\end{array}$ \\
\hline$>3$ & $\begin{array}{l}5.01 \\
(4.76,5.26)\end{array}$ & $\begin{array}{l}3.39 \\
(3.24,3.53)\end{array}$ & $\begin{array}{l}0.43 \\
(0.37,0.49)\end{array}$ & $\begin{array}{l}2.38 \\
(2.23,2.52)\end{array}$ & $\begin{array}{l}1.16 \\
(1.08,1.24)\end{array}$ & $\begin{array}{l}0.32 \\
(0.30,0.33)\end{array}$ & $\begin{array}{l}0.02 \\
(0.01,0.03)\end{array}$ & $\begin{array}{l}0.32 \\
(0.32,0.32)\end{array}$ & $\begin{array}{l}-0.06 \\
(-0.08,-0.05)\end{array}$ & $\begin{array}{l}-1.10 \\
(-1.17,-1.02)\end{array}$ \\
\hline
\end{tabular}


S4.5 Odds ratios and confidence intervals for type 2 diabetes, basic model. Reference: no alcohol consumption.

\begin{tabular}{|l|l|}
\hline glasses/day & T2D \\
\hline$>0-1$ & $\begin{array}{l}0.59 \\
(0.57,0.61)\end{array}$ \\
\hline$>1-2$ & $\begin{array}{l}0.44 \\
(0.42,0.46)\end{array}$ \\
\hline$>2-3$ & $0.43(0.4,0.45)$ \\
\hline$>3$ & $0.47(0.45,0.5)$ \\
\hline
\end{tabular}

S4.6 Odds ratios and confidence intervals for type 2 diabetes, fully-adjusted model. Reference: no alcohol consumption.

\begin{tabular}{|l|l|}
\hline glasses/day & T2D \\
\hline & $\begin{array}{l}0.81 \\
(0.77,0.84)\end{array}$ \\
\hline$>0-1$ & $\begin{array}{l}0.69 \\
(0.65,0.73)\end{array}$ \\
\hline$>1-2$ & $\begin{array}{l}0.68 \\
(0.63,0.73)\end{array}$ \\
\hline$>2-3$ & 0.75 \\
& $(0.7,0.81)$ \\
\hline
\end{tabular}


S4.7 Hazard ratios and confidence intervals for binary measures (diseases and events), basic model. Reference: no alcohol consumption.

\begin{tabular}{|c|c|c|c|c|c|c|c|c|}
\hline glasses/day & MI & ALLSTROKE & ISTROKE & HSTROKE & HF & AFIB & CVD & Death \\
\hline$>0-1$ & $\begin{array}{l}0.80 \\
(0.76,0.84)\end{array}$ & $\begin{array}{l}0.89 \\
(0.84,0.95)\end{array}$ & $\begin{array}{l}0.85 \\
(0.78,0.93)\end{array}$ & $\begin{array}{l}0.93 \\
(0.82,1.05)\end{array}$ & $\begin{array}{l}0.69 \\
(0.64,0.74)\end{array}$ & $\begin{array}{l}0.88 \\
(0.84,0.92)\end{array}$ & $\begin{array}{l}0.83 \\
(0.81,0.86)\end{array}$ & $\begin{array}{l}0.77 \\
(0.74,0.80)\end{array}$ \\
\hline$>1-2$ & $\begin{array}{l}0.70 \\
(0.66,0.74)\end{array}$ & $\begin{array}{l}0.83 \\
(0.78,0.89)\end{array}$ & $\begin{array}{l}0.86 \\
(0.78,0.95)\end{array}$ & \begin{tabular}{|l}
0.79 \\
$(0.68,0.92)$
\end{tabular} & $\begin{array}{l}0.61 \\
(0.56,0.66)\end{array}$ & $\begin{array}{l}0.89 \\
(0.85,0.94)\end{array}$ & $\begin{array}{l}0.78 \\
(0.75,0.80)\end{array}$ & $\begin{array}{l}0.71 \\
(0.68,0.74)\end{array}$ \\
\hline$>2-3$ & $\begin{array}{l}0.68 \\
(0.63,0.72)\end{array}$ & $\begin{array}{l}0.79 \\
(0.72,0.87)\end{array}$ & $\begin{array}{l}0.75 \\
(0.65,0.86)\end{array}$ & $\begin{array}{l}0.93 \\
(0.77,1.12)\end{array}$ & $\begin{array}{l}0.63 \\
(0.57,0.70)\end{array}$ & $\begin{array}{l}0.94 \\
(0.88,0.99)\end{array}$ & $\begin{array}{l}0.79 \\
(0.75,0.82)\end{array}$ & $\begin{array}{l}0.71 \\
(0.67,0.75)\end{array}$ \\
\hline$>3$ & $\begin{array}{l}0.69 \\
(0.65,0.74)\end{array}$ & $\begin{array}{l}0.98 \\
(0.90,1.08)\end{array}$ & $\begin{array}{l}1.00 \\
(0.88,1.14)\end{array}$ & $\begin{array}{l}1.07 \\
(0.88,1.29)\end{array}$ & $\begin{array}{l}0.75 \\
(0.68,0.83)\end{array}$ & $\begin{array}{l}1.10 \\
(1.04,1.17)\end{array}$ & $\begin{array}{l}0.88 \\
(0.85,0.92)\end{array}$ & $\begin{array}{l}0.91 \\
(0.87,0.96)\end{array}$ \\
\hline
\end{tabular}

S4.8 Hazard ratios and confidence intervals for binary measures (diseases and events), fully-adjusted model. Reference: no alcohol consumption.

\begin{tabular}{|c|c|c|c|c|c|c|c|c|}
\hline glasses/day & MI & ALLSTROKE & ISTROKE & HSTROKE & HF & AFIB & CVD & Death \\
\hline$>0-1$ & $\begin{array}{l}0.89 \\
(0.84,0.95)\end{array}$ & $\begin{array}{l}0.91 \\
(0.85,0.98)\end{array}$ & $\begin{array}{l}0.87 \\
(0.78,0.97)\end{array}$ & $\begin{array}{l}0.91 \\
(0.78,1.06)\end{array}$ & $\begin{array}{l}0.81 \\
(0.74,0.88)\end{array}$ & $\begin{array}{l}0.98 \\
(0.93,1.03)\end{array}$ & $\begin{array}{l}0.91 \\
(0.88,0.95)\end{array}$ & $\begin{array}{l}0.80 \\
(0.76,0.84)\end{array}$ \\
\hline$>1-2$ & $\begin{array}{l}0.82 \\
(0.77,0.88)\end{array}$ & $\begin{array}{l}0.87 \\
(0.80,0.95)\end{array}$ & $\begin{array}{l}0.93 \\
(0.82,1.05)\end{array}$ & $\begin{array}{l}0.76 \\
(0.63,0.91)\end{array}$ & $\begin{array}{l}0.73 \\
(0.66,0.81)\end{array}$ & $\begin{array}{l}1.00 \\
(0.95,1.07)\end{array}$ & $\begin{array}{l}0.87 \\
(0.84,0.91)\end{array}$ & $\begin{array}{l}0.77 \\
(0.73,0.82)\end{array}$ \\
\hline$>2-3$ & $\begin{array}{l}0.81 \\
(0.74,0.88)\end{array}$ & $\begin{array}{l}0.85 \\
(0.76,0.95)\end{array}$ & $\begin{array}{l}0.81 \\
(0.69,0.95)\end{array}$ & $\begin{array}{l}1.00 \\
(0.80,1.24)\end{array}$ & $\begin{array}{l}0.78 \\
(0.68,0.88)\end{array}$ & $\begin{array}{l}1.04 \\
(0.97,1.12)\end{array}$ & $\begin{array}{l}0.89 \\
(0.85,0.93)\end{array}$ & $\begin{array}{l}0.78 \\
(0.73,0.84)\end{array}$ \\
\hline$>3$ & $\begin{array}{l}0.85 \\
(0.78,0.92)\end{array}$ & $\begin{array}{l}1.02 \\
(0.91,1.14)\end{array}$ & $\begin{array}{l}1.04 \\
(0.89,1.22)\end{array}$ & $\begin{array}{l}1.00 \\
(0.79,1.26)\end{array}$ & $\begin{array}{l}0.91 \\
(0.80,1.03)\end{array}$ & $\begin{array}{l}1.20 \\
(1.11,1.29)\end{array}$ & $\begin{array}{l}0.99 \\
(0.94,1.05)\end{array}$ & $\begin{array}{l}1.04 \\
(0.97,1.11)\end{array}$ \\
\hline
\end{tabular}




\section{S5. Mendelian randomization results}

S5.1 Characteristics of strata for the Mendelian randomization (MR) analysis

The total column is repeated from Table 1.

\begin{tabular}{|c|c|c|c|c|c|}
\hline Variable & MR - total & MR - male & MR - female & MR - nonsmokers & MR - smokers \\
\hline $\mathrm{n}$ & 337484 & 156248 & 181236 & 183826 & 33977 \\
\hline \multicolumn{6}{|l|}{ Sex } \\
\hline Female & $181236(53.7)$ & $0(0)$ & $181236(100)$ & $107418(58.4)$ & $15577(45.8)$ \\
\hline Male & $156248(46.3)$ & $156248(100)$ & $0(0)$ & 76408 (41.6) & $18400(54.2)$ \\
\hline Age (years) & $67.6(8)$ & $67.9(8.1)$ & $67.4(7.9)$ & $66.9(8.1)$ & $65.9(8.1)$ \\
\hline \multicolumn{6}{|l|}{ Region } \\
\hline England & 297645 (88.2) & $138232(88.5)$ & $159413(88)$ & $161683(88)$ & $29350(86.4)$ \\
\hline Wales & $14824(4.4)$ & $6822(4.4)$ & $8002(4.4)$ & $8236(4.5)$ & $1614(4.8)$ \\
\hline Scotland & $25015(7.4)$ & 11194 (7.2) & $13821(7.6)$ & $13907(7.6)$ & $3013(8.9)$ \\
\hline Townsend index & $-1.6(2.9)$ & $-1.5(3)$ & $-1.6(2.9)$ & $-1.9(2.7)$ & $-0.1(3.5)$ \\
\hline \multicolumn{6}{|l|}{ Ethnic group } \\
\hline White & $337484(100)$ & $156248(100)$ & $181236(100)$ & $183826(100)$ & 33977 (100) \\
\hline Asian or Asian British & $0(0)$ & $0(0)$ & $0(0)$ & $0(0)$ & $0(0)$ \\
\hline Black or Black British & $0(0)$ & $0(0)$ & $0(0)$ & $0(0)$ & $0(0)$ \\
\hline
\end{tabular}




\begin{tabular}{|c|c|c|c|c|c|}
\hline Mixed or other & $0(0)$ & $0(0)$ & $0(0)$ & $0(0)$ & $0(0)$ \\
\hline Don't know/refused & $0(0)$ & $0(0)$ & $0(0)$ & $0(0)$ & $0(0)$ \\
\hline \multicolumn{6}{|l|}{ Smoking status } \\
\hline Never-smoker & $183826(54.5)$ & 76408 (48.9) & $107418(59.3)$ & $183826(100)$ & $0(0)$ \\
\hline Current smoker & 33977 (10.1) & $18400(11.8)$ & $15577(8.6)$ & $0(0)$ & 33977 (100) \\
\hline Former smoker & 118505 (35.1) & $60883(39)$ & $57622(31.8)$ & $0(0)$ & $0(0)$ \\
\hline No response & $1176(0.3)$ & $557(0.4)$ & $619(0.3)$ & $0(0)$ & $0(0)$ \\
\hline \multicolumn{6}{|l|}{ Drinking status } \\
\hline Never-drinker & $10392(3.1)$ & $2623(1.7)$ & 7769 (4.3) & $8234(4.5)$ & $674(2)$ \\
\hline Current drinker & $315257(93.4)$ & $148479(95)$ & $166778(92)$ & $170381(92.7)$ & 31430 (92.5) \\
\hline Former drinker & $11543(3.4)$ & 5017 (3.2) & $6526(3.6)$ & $5084(2.8)$ & $1806(5.3)$ \\
\hline No response & $292(0.1)$ & $129(0.1)$ & $163(0.1)$ & $127(0.1)$ & $67(0.2)$ \\
\hline \multicolumn{6}{|l|}{ Drinking frequency } \\
\hline Daily or almost daily & $72270(21.4)$ & $41339(26.5)$ & $30931(17.1)$ & $30020(16.3)$ & 9136 (26.9) \\
\hline Three or four times a week & $81462(24.1)$ & $42266(27.1)$ & $39196(21.6)$ & $44049(24)$ & 6542 (19.3) \\
\hline Once or twice a week & 88747 (26.3) & $40983(26.2)$ & $47764(26.4)$ & $52425(28.5)$ & 7865 (23.1) \\
\hline One to three times a month & 37367 (11.1) & $13662(8.7)$ & $23705(13.1)$ & $22816(12.4)$ & 3720 (10.9) \\
\hline Special occasions only & $35411(10.5)$ & 10229 (6.5) & $25182(13.9)$ & $21071(11.5)$ & 4167 (12.3) \\
\hline
\end{tabular}




\begin{tabular}{|c|c|c|c|c|c|}
\hline Never & $21991(6.5)$ & 7656 (4.9) & 14335 (7.9) & 13354 (7.3) & $2491(7.3)$ \\
\hline No response & $236(0.1)$ & $113(0.1)$ & $123(0.1)$ & $91(0)$ & $56(0.2)$ \\
\hline $\begin{array}{l}\text { Alcohol (weekly equivalent glasses } \\
\text { of wine) }\end{array}$ & $8.1(9.5)$ & $11.1(11.2)$ & $5.4(6.6)$ & $6.5(7.8)$ & 10.9 (13.3) \\
\hline Systolic blood pressure $(\mathrm{mmHg})$ & $140.2(19.7)$ & $143.2(18.5)$ & $137.6(20.3)$ & $139.7(19.5)$ & $137.5(19.5)$ \\
\hline Diastolic blood pressure $(\mathrm{mmHg})$ & $82.2(10.7)$ & $84.1(10.5)$ & $80.6(10.5)$ & $82.2(10.6)$ & $81.6(10.9)$ \\
\hline Body mass index $\left(\mathrm{kg} / \mathrm{m}^{\wedge} 2\right)$ & $27.4(4.7)$ & $27.8(4.2)$ & $27(5.1)$ & $27.1(4.7)$ & $27.1(4.8)$ \\
\hline Waist circumference (cm) & $90.3(13.5)$ & $97(11.3)$ & $84.6(12.5)$ & $88.7(13.2)$ & $91.2(13.5)$ \\
\hline Body fat percentage & $31.4(8.5)$ & $25.3(5.8)$ & $36.6(6.9)$ & $31.4(8.6)$ & $29.9(8.6)$ \\
\hline Cholesterol (mmol/L) & $5.7(1.1)$ & $5.5(1.1)$ & $5.9(1.1)$ & $5.7(1.1)$ & $5.7(1.2)$ \\
\hline LDL (mmol/L) & $3.6(0.9)$ & $3.5(0.9)$ & $3.6(0.9)$ & $3.6(0.9)$ & $3.6(0.9)$ \\
\hline $\mathrm{HDL}(\mathrm{mmol} / \mathrm{L})$ & $1.5(0.4)$ & $1.3(0.3)$ & $1.6(0.4)$ & $1.5(0.4)$ & $1.4(0.4)$ \\
\hline Triglycerides (mmol/L) & $1.8(1)$ & $2(1.1)$ & $1.6(0.9)$ & $1.7(1)$ & $2(1.2)$ \\
\hline $\mathrm{HbA} 1 \mathrm{c}(\mathrm{mmol} / \mathrm{mol})$ & $36(6.5)$ & $36.3(7.3)$ & $35.7(5.7)$ & $35.5(6)$ & $37.1(7.2)$ \\
\hline Glucose (mmol/L) & $5.1(1.2)$ & $5.2(1.4)$ & $5.1(1)$ & $5.1(1.1)$ & $5.1(1.2)$ \\
\hline Type 2 diabetes & $15493(4.6)$ & $9879(6.3)$ & $5614(3.1)$ & $6402(3.5)$ & $1715(5)$ \\
\hline Coronary heart disease & $16102(4.8)$ & $12260(7.8)$ & $3842(2.1)$ & 6057 (3.3) & $2274(6.7)$ \\
\hline All stroke & $8044(2.4)$ & 4825 (3.1) & 3219 (1.8) & 3498 (1.9) & $1193(3.5)$ \\
\hline
\end{tabular}




\begin{tabular}{|l|l|l|l|l|}
\hline Ischemic stroke & $3427(1)$ & $2195(1.4)$ & $1232(0.7)$ & $1434(0.8)$ \\
\hline Hemorrhagic stroke & $1877(0.6)$ & $1002(0.6)$ & $875(0.5)$ & $811(0.4)$ \\
\hline Heart failure & $5921(1.8)$ & $4116(2.6)$ & $1805(1)$ & $2145(1.2)$ \\
\hline Atrial fibrillation & $15483(4.6)$ & $10425(6.7)$ & $5058(2.8)$ & $6766(3.7)$ \\
\hline Any cardiovascular disease & $35499(10.5)$ & $24023(15.4)$ & $11476(6.3)$ & $14911(8.1)$ \\
\hline All-cause death & $13700(4.1)$ & $8410(5.4)$ & $5290(2.9)$ & $5102(2.8)$ \\
\hline ADH1B status & & & & $1530(4.5)$ \\
\hline Wildtype & $322519(95.6)$ & $149158(95.5)$ & $173361(95.7)$ & $175669(95.6)$ \\
\hline Carrier & $14777(4.4)$ & $7013(4.5)$ & $7764(4.3)$ & $8056(4.4)$ \\
\hline Homozygous minor allele & $188(0.1)$ & $77(0)$ & $111(0.1)$ & $13.3)$ \\
\hline
\end{tabular}




\section{S5.2 Sensitivity analysis: Meds for diabetes, hypertension, and lipids}

Our sensitivity analysis showed little difference in the overall outcome and no difference in the ultimate finding when excluding individuals with medications for diabetes, hypertension, or lowering of lipids.

\begin{tabular}{|l|l|}
\hline Group & HbA1C effect for +1 drink/day \\
\hline Everyone $(n=337,484)$ & $-0.420 \mathrm{mmol} / \mathrm{mol}(-0.781,-0.059)$ \\
\hline $\begin{array}{l}\text { Diabetes medication takers excluded } \\
(n=325,466 ; 96 \%)\end{array}$ & $-0.412 \mathrm{mmol} / \mathrm{mol}(-0.684,-0.140)$ \\
\hline
\end{tabular}

\begin{tabular}{|l|l|l|}
\hline Group & $\begin{array}{l}\text { Systolic BP effect for } \\
\mathbf{+ 1} \text { drink/day }\end{array}$ & $\begin{array}{l}\text { Diastolic BP effect for } \\
+1 \text { drink/day }\end{array}$ \\
\hline Everyone $(n=337,484)$ & $\begin{array}{l}2.99 \mathrm{mmHg} \\
(1.90,4.09)\end{array}$ & $\begin{array}{l}0.492 \mathrm{mmHg} \\
(-0.102,1.09)\end{array}$ \\
\hline $\begin{array}{l}\text { Hypertensive medication takers } \\
\text { excluded }(\mathrm{n}=267,379 ; 79 \%)\end{array}$ & $\begin{array}{l}2.77 \mathrm{mmHg} \\
(1.45,4.09)\end{array}$ & $\begin{array}{l}0.573 \mathrm{mmHg} \\
(-0.149,1.30)\end{array}$ \\
\hline
\end{tabular}

\begin{tabular}{|l|l|l|l|}
\hline Group & $\begin{array}{l}\text { LDL effect for } \\
+1 \text { drink/day }\end{array}$ & $\begin{array}{l}\text { TG effect for } \\
+1 \text { drink/day }\end{array}$ & $\begin{array}{l}\text { HDL effect for } \\
\text { +1 drink/day }\end{array}$ \\
\hline Everyone $(\mathrm{n}=337,484)$ & $\begin{array}{l}0.155 \mathrm{mmol} / \mathrm{L} \\
(0.107,0.204)\end{array}$ & $\begin{array}{l}-0.059 \mathrm{mmol} / \mathrm{L} \\
(-0.012,-0.002)\end{array}$ & $\begin{array}{l}0.0013 \mathrm{mmol} / \mathrm{L} \\
(-0.021,0.023)\end{array}$ \\
\hline $\begin{array}{l}\text { Lipid lowering medication takers } \\
\text { excluded }(\mathrm{n}=278,875 ; 83 \%)\end{array}$ & $\begin{array}{l}0.219 \mathrm{mmol} / \mathrm{L} \\
(0.164,0.273)\end{array}$ & $\begin{array}{l}-0.080 \mathrm{mmol} / \mathrm{L} \\
(-0.147,-0.013)\end{array}$ & $\begin{array}{l}0.0095 \mathrm{mmol} / \mathrm{L} \\
(-0.017,0.036)\end{array}$ \\
\hline
\end{tabular}

S5.3 Additional analysis of blood count data by instrument variable group

\begin{tabular}{|l|l|l|l|l|}
\hline Variable & $\begin{array}{l}\text { Heterozygous + homozygous } \\
\text { group }\end{array}$ & Wildtype & p-value & F statistic \\
\hline Hemoglobin $(\mathrm{g} / \mathrm{dL})$ & 14.23 & 14.21 & 0.0179 & 5.6 \\
\hline Hematocrit (\%) & 41.24 & 41.15 & 0.00237 & 9.2 \\
\hline $\begin{array}{l}\text { Mean corpuscular } \\
\text { volume (fL) }\end{array}$ & 91.08 & 91.35 & $2.37 \mathrm{e}-13$ & 53.7 \\
\hline
\end{tabular}


1. Grant, B.F., et al., Prevalence of 12-Month Alcohol Use, High-Risk Drinking, and DSM-IV Alcohol Use Disorder in the United States, 2001-2002 to 2012-2013: Results From the National Epidemiologic Survey on Alcohol and Related Conditions. JAMA Psychiatry, 2017. 74(9): p. 911-923.

2. NHS. Part 4: Drinking behaviours among adults. Statistics on Alcohol, England 2020 2020 [cited 2020 October 8]; Available from: https://digital.nhs.uk/data-andinformation/publications/statistical/statistics-on-alcohol/2020/part-4.

3. Koppes, L.L., et al., Moderate alcohol consumption lowers the risk of type 2 diabetes: a meta-analysis of prospective observational studies. Diabetes Care, 2005. 28(3): p. 71925.

4. $\quad \mathrm{Li}, \mathrm{X} . \mathrm{H}$., et al., Association between alcohol consumption and the risk of incident type 2 diabetes: a systematic review and dose-response meta-analysis. Am J Clin Nutr, 2016. 103(3): p. 818-29.

5. Friedman, L.A. and A.W. Kimball, Coronary heart disease mortality and alcohol consumption in Framingham. Am J Epidemiol, 1986. 124(3): p. 481-9.

6. Gordon, T. and W.B. Kannel, Drinking habits and cardiovascular disease: the Framingham Study. Am Heart J, 1983. 105(4): p. 667-73.

7. Wood, A.M., et al., Risk thresholds for alcohol consumption: combined analysis of individual-participant data for 599912 current drinkers in 83 prospective studies. Lancet, 2018. 391(10129): p. 1513-1523.

8. Sacco, R.L., et al., The protective effect of moderate alcohol consumption on ischemic stroke. Jama, 1999. 281(1): p. 53-60.

9. Reynolds, K., et al., Alcohol consumption and risk of stroke: a meta-analysis. Jama, 2003. 289(5): p. 579-88.

10. Stampfer, M.J., et al., A prospective study of moderate alcohol consumption and the risk of coronary disease and stroke in women. N Engl J Med, 1988. 319(5): p. 267-73.

11. Gallagher, C., et al., Alcohol and incident atrial fibrillation - A systematic review and meta-analysis. Int J Cardiol, 2017. 246: p. 46-52.

12. Walsh, C.R., et al., Alcohol consumption and risk for congestive heart failure in the Framingham Heart Study. Ann Intern Med, 2002. 136(3): p. 181-91.

13. Marmot, M.G., et al., Alcohol and blood pressure: the INTERSALT study. Bmj, 1994. 308(6939): p. 1263-7.

14. Castelli, W.P., et al., Alcohol and blood lipids. The cooperative lipoprotein phenotyping study. Lancet, 1977. 2(8030): p. 153-5.

15. Hartung, G.H., et al., Effect of alcohol intake on high-density lipoprotein cholesterol levels in runners and inactive men. Jama, 1983. 249(6): p. 747-50.

16. Schrieks, I.C., et al., The effect of alcohol consumption on insulin sensitivity and glycemic status: a systematic review and meta-analysis of intervention studies. Diabetes Care, 2015. 38(4): p. 723-32.

17. Voight, B.F., et al., Plasma HDL cholesterol and risk of myocardial infarction: a mendelian randomisation study. Lancet, 2012. 380(9841): p. 572-80.

18. Rosenson, R.S., The High-Density Lipoprotein Puzzle: Why Classic Epidemiology, Genetic Epidemiology, and Clinical Trials Conflict? Arterioscler Thromb Vasc Biol, 2016. 36(5): p. 777-82.

19. Armitage, J., M.V. Holmes, and D. Preiss, Cholesteryl Ester Transfer Protein Inhibition for Preventing Cardiovascular Events: JACC Review Topic of the Week. J Am Coll Cardiol, 2019. 73(4): p. 477-487.

20. Emberson, J.R. and D.A. Bennett, Effect of alcohol on risk of coronary heart disease and stroke: causality, bias, or a bit of both? Vasc Health Risk Manag, 2006. 2(3): p. 239-49.

21. Sesso, H.D., et al., Alcohol consumption and the risk of hypertension in women and men. Hypertension, 2008. 51(4): p. 1080-7. 
22. Sudlow, C., et al., UK biobank: an open access resource for identifying the causes of a wide range of complex diseases of middle and old age. PLoS Med, 2015. 12(3): p. e1001779.

23. NHS. Alcohol Units. [cited 2017 November 29]; Available from: https://www.nhs.uk/livewell/alcohol-support/calculating-alcohol-units/.

24. Karczewski, K.J., et al., The mutational constraint spectrum quantified from variation in 141,456 humans. Nature, 2020. 581(7809): p. 434-443.

25. Genome Aggregation Database. [cited 2020 October 24]; Available from: https://gnomad.broadinstitute.org/variant/4-100239319-T-C?dataset=gnomad r2 1.

26. Rimm, E.B., et al., Moderate alcohol intake and lower risk of coronary heart disease: meta-analysis of effects on lipids and haemostatic factors. Bmj, 1999. 319(7224): p. 1523-8.

27. Lawlor, D.A., et al., Exploring causal associations between alcohol and coronary heart disease risk factors: findings from a Mendelian randomization study in the Copenhagen General Population Study. Eur Heart J, 2013. 34(32): p. 2519-28.

28. Holmes, M.V., et al., Association between alcohol and cardiovascular disease: Mendelian randomisation analysis based on individual participant data. Bmj, 2014. 349: p. g4164.

29. Larsson, S.C., et al., Alcohol Consumption and Cardiovascular Disease: A Mendelian Randomization Study. Circ Genom Precis Med, 2020. 13(3): p. e002814.

30. Lindenbaum, J. and M.J. Roman, Nutritional anemia in alcoholism. Am J Clin Nutr, 1980. 33(12): p. 2727-35.

31. Sakamoto, N., et al., Associations of anemia and hemoglobin with hemoglobin A1c among non-diabetic workers in Japan. J Diabetes Investig, 2020. 11(3): p. 719-725.

32. Millwood, I.Y., et al., Conventional and genetic evidence on alcohol and vascular disease aetiology: a prospective study of 500000 men and women in China. Lancet, 2019. 393(10183): p. 1831-1842.

33. Peng, M., et al., Alcohol consumption and diabetes risk in a Chinese population: a Mendelian randomization analysis. Addiction, 2019. 114(3): p. 436-449.

34. Davey Smith, G. and G. Hemani, Mendelian randomization: genetic anchors for causal inference in epidemiological studies. Hum Mol Genet, 2014. 23(R1): p. R89-98.

35. Fry, A., et al., Comparison of Sociodemographic and Health-Related Characteristics of UK Biobank Participants With Those of the General Population. Am J Epidemiol, 2017. 186(9): p. 1026-1034.

36. Grogan, J.R. and M.S. Kochar, Alcohol and hypertension. Arch Fam Med, 1994. 3(2): p. 150-4.

37. Brien, S.E., et al., Effect of alcohol consumption on biological markers associated with risk of coronary heart disease: systematic review and meta-analysis of interventional studies. Bmj, 2011. 342: p. d636.

38. Wood, P.D., et al., Changes in plasma lipids and lipoproteins in overweight men during weight loss through dieting as compared with exercise. N Engl J Med, 1988. 319(18): $p$. 1173-9.

39. Ballard, H.S., The hematological complications of alcoholism. Alcohol Health Res World, 1997. 21(1): p. 42-52.

40. Alcohol use and burden for 195 countries and territories, 1990-2016: a systematic analysis for the Global Burden of Disease Study 2016. Lancet, 2018. 392(10152): p. 1015-1035.

41. Office of Disease Prevention and Health Promotion. Alcohol. Dietary Guidelines 20152020 [cited 2020 October 12]; Available from: https://health.gov/our-work/foodnutrition/2015-2020-dietary-guidelines/guidelines/appendix-9/. 
42. Spiegelman, D., et al., The Moderate Alcohol and Cardiovascular Health Trial (MACH15): Design and methods for a randomized trial of moderate alcohol consumption and cardiometabolic risk. Eur J Prev Cardiol, 2020: p. 2047487320912376.

43. Cardiovascular Disease Knowledge Portal. [cited 2020 February 7]; Available from: http://www.broadcvdi.org/home/portalHome.

44. Cerebrovascular Disease Knowledge Portal, NINDS grant \# 1R24NS092983. [cited 2020 February 7]; Available from:

http://www.cerebrovascularportal.org/home/portalHome.

45. Type 2 Diabetes Knowledge Portal. [cited 2020 February 7]; Available from: http://www.type2diabetesgenetics.org/.

46. Nikpay, M., et al., A comprehensive 1,000 Genomes-based genome-wide association meta-analysis of coronary artery disease. Nat Genet, 2015. 47(10): p. 1121-1130.

47. Malik, R., et al., Multiancestry genome-wide association study of 520,000 subjects identifies 32 loci associated with stroke and stroke subtypes. Nat Genet, 2018. 50(4): p. 524-537.

48. Shah, S., et al., Genome-wide association and Mendelian randomisation analysis provide insights into the pathogenesis of heart failure. Nat Commun, 2020. 11(1): p. 163.

49. Roselli, C., et al., Multi-ethnic genome-wide association study for atrial fibrillation. Nat Genet, 2018. 50(9): p. 1225-1233.

50. Mahajan, A., et al., Fine-mapping type 2 diabetes loci to single-variant resolution using high-density imputation and islet-specific epigenome maps. Nat Genet, 2018. 50(11): p. 1505-1513.

51. Locke, A.E., et al., Exome sequencing of Finnish isolates enhances rare-variant association power. Nature, 2019. 572(7769): p. 323-328.

52. Soranzo, N., et al., Common variants at 10 genomic loci influence hemoglobin $A_{1}(C)$ levels via glycemic and nonglycemic pathways. Diabetes, 2010. 59(12): p. 3229-39.

53. Turcot, V., et al., Protein-altering variants associated with body mass index implicate pathways that control energy intake and expenditure in obesity. Nat Genet, 2018. 50(1): p. 26-41.

54. Pulit, S.L., et al., Meta-analysis of genome-wide association studies for body fat distribution in 694649 individuals of European ancestry. Hum Mol Genet, 2019. 28(1): p. 166-174.

55. Accelerating Medicines Partnership. Type 2 Diabetes Knowledge Portal News 2018 [cited 2020 October 6]; Available from: http://t2d-geneticsportal.blogspot.com/2018/02/federation-brings-three-new-datasets-to.html.

56. Lu, Y., et al., New loci for body fat percentage reveal link between adiposity and cardiometabolic disease risk. Nat Commun, 2016. 7: p. 10495.

57. Liu, D.J., et al., Exome-wide association study of plasma lipids in $>300,000$ individuals. Nat Genet, 2017. 49(12): p. 1758-1766. 
Figure 1a: Effect of 1 additional drink/day

Systolic blood pressure $(\mathrm{mmHg})$

UK Biobank

$$
\begin{array}{r}
2.99[1.90,4.09] \\
-0.08[-0.57,0.41] \\
0.49[-0.10,1.09] \\
-0.34[-0.83,0.15] \\
0.87[0.61,1.13] \\
0.03[-0.11,0.18] \\
0.10[0.07,0.13] \\
1.34[0.61,2.07] \\
0.46[0.13,0.79] \\
1.68[1.21,2.14] \\
-0.07[-0.27,0.13] \\
-0.45[-1.09,0.20]
\end{array}
$$$$
\text { FinnMetSeq }
$$

Diastolic blood pressure $(\mathrm{mmHg})$

UK Biobank

FinnMetSeq

Body mass index $\left(\mathrm{kg} / \mathrm{m}^{\wedge} 2\right)$

UK Biobank

GIANT

GIANT-UK Biobank MA

Waist circumference $(\mathrm{cm})$

UK Biobank

EXTEND GWAS

Body fat percentage

UK Biobank

BFP GWAS

FinnMetSeq

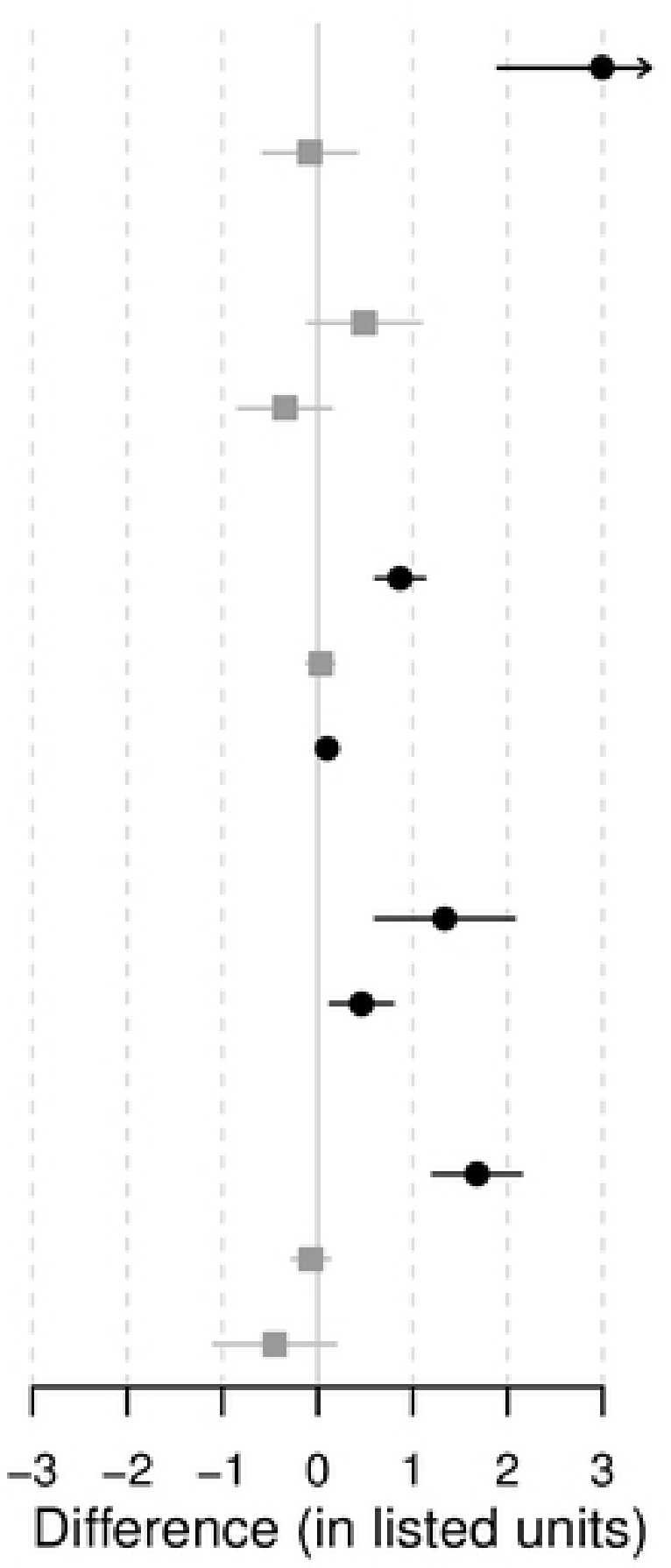

Figure $1 \mathrm{a}$ 


\section{Figure 1b: Effect of 1 additional drink/day}

Cholesterol (mmol/L)

UK Biobank

GLGC

LDL ( $\mathrm{mmol} / \mathrm{L})$

UK Biobank

GLGC

$\mathrm{HDL}(\mathrm{mmol} / \mathrm{L})$

UK Biobank

GLGC

Triglycerides ( $\mathrm{mmol} / \mathrm{L})$

UK Biobank

GLGC

$\mathrm{HbA1C}(\mathrm{mmol} / \mathrm{mol})$

UK Biobank

MAGIC

$$
\begin{aligned}
& 0.16[0.10,0.22] \\
& -0.04[-0.34,0.26] \\
& 0.16[0.11,0.20] \\
& 0.00[-0.30,0.30] \\
& 0.00[-0.02,0.02] \\
& 0.20[-0.10,0.50] \\
& -0.06[-0.12,0.00] \\
& -0.26[-0.56,0.03] \\
& -0.42[-0.78,-0.06] \\
& -0.10[-0.41,0.21]
\end{aligned}
$$

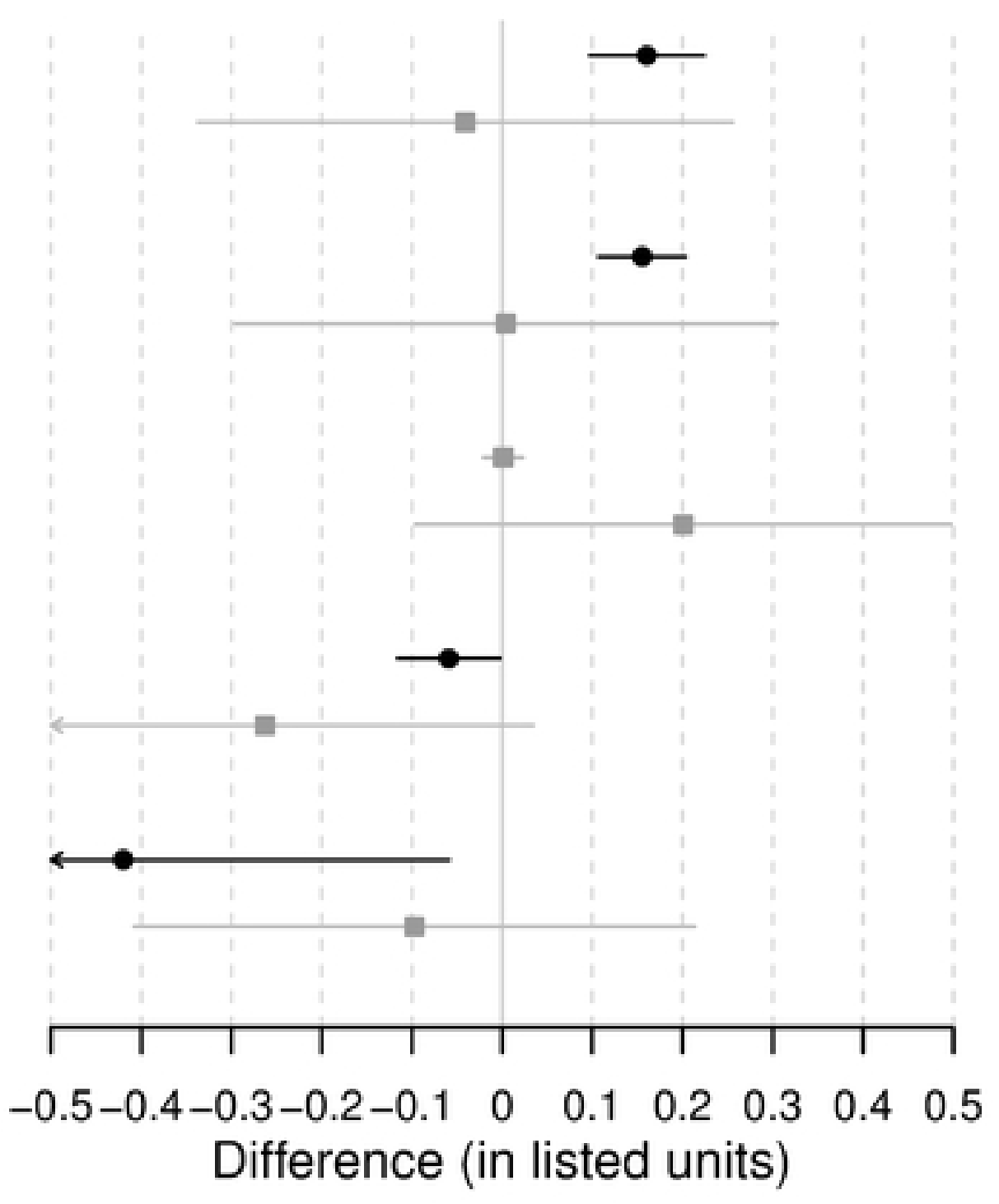


Figure 1c: Effect of 1 additional drink/day

Myocardial infarction

UK Biobank

CARDIoGRAMplusC4D GWAS

\section{Stroke}

UK Biobank

MEGASTROKE

Ischemic stroke

UK Biobank

MEGASTROKE

Hemmorhagic stroke

UK Biobank

Heart failure

UK Biobank

HERMES GWAS

Atrial fibrillation

UK Biobank

AF HRC 2018 GWAS

Type 2 diabetes

UK Biobank

DIAMANTE T2D GWAS

Any cardiovascular disease

UK Biobank

All-cause death

UK Biobank
$1.50[1.15,1.96]$

$1.11[0.97,1.27]$

$1.52[1.04,2.21]$

$1.14[1.03,1.26]$

$1.33[0.76,2.33]$

$1.14[1.02,1.27]$

$1.82[0.83,4.01]$

$1.50[0.97,2.31]$

$1.14[0.95,1.37]$

$1.27[0.97,1.65]$

$1.07[0.96,1.18]$

$1.26[0.97,1.65]$

$1.25[1.10,1.43]$

$1.43[1.19,1.72]$

$1.41[1.06,1.88]$

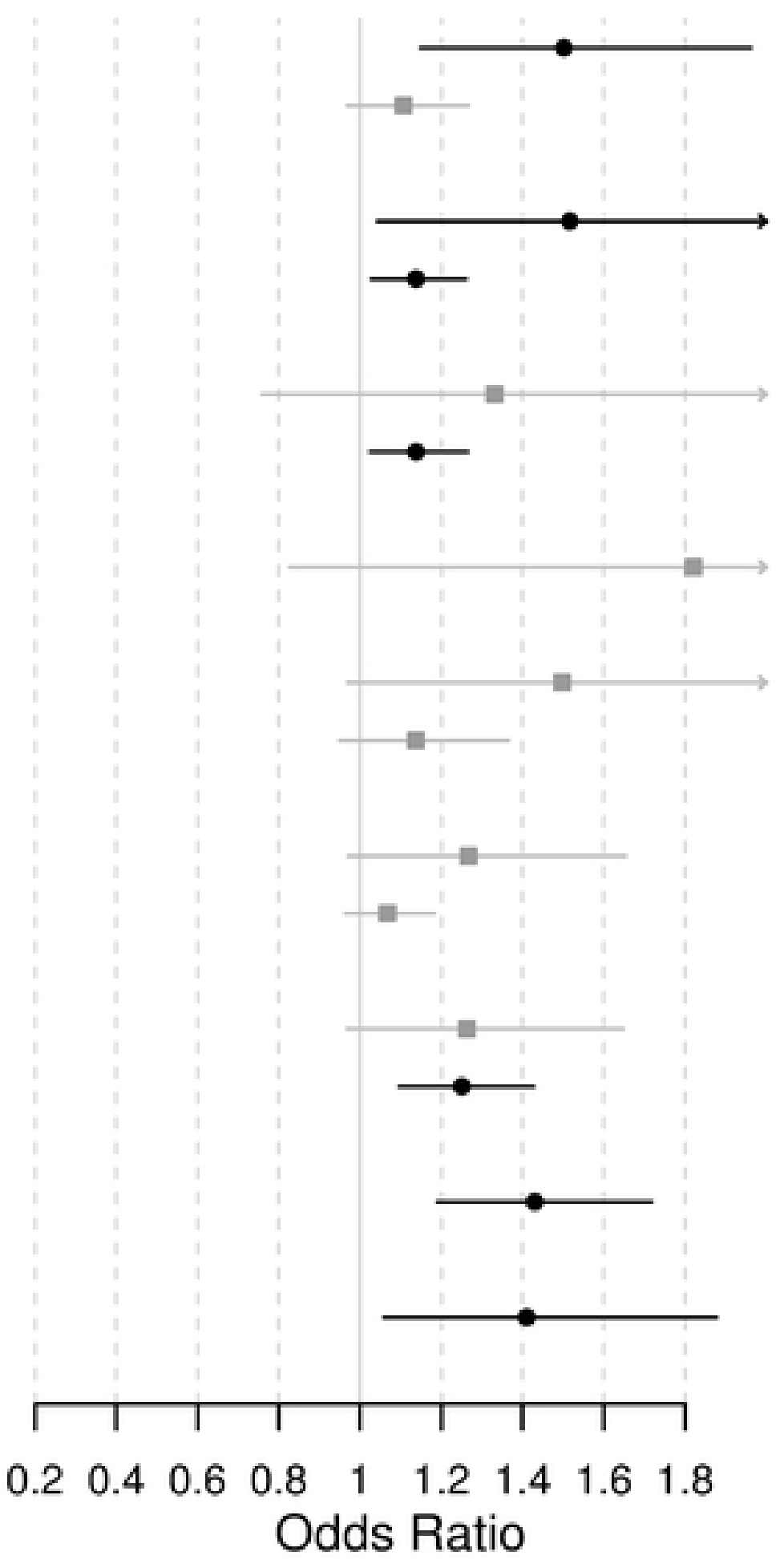


Figure 2a: Effect of 1 additional drink/day

Systolic blood pressure $(\mathrm{mmHg})$

all

male

female

current smokers

never-smokers

Diastolic blood pressure $(\mathrm{mmHg})$

all

male

female

current smokers

never-smokers

Body mass index $\left(\mathrm{kg} / \mathrm{m}^{\wedge} 2\right)$

all

male

female

current smokers

never-smokers

Waist circumference $(\mathrm{cm})$

all

male

female

current smokers

never-smokers

Body fat percentage

all

male

female

current smokers

never-smokers
$2.99[1.90,4.09]$

$2.82[1.69,3.95]$

$3.54[1.52,5.56$

$3.02[0.92,5.12]$

2.26 [ 0.58, 3.94]

$0.49[-0.10,1.09]$

$0.77[0.13,1.42]$

$0.33[-0.72,1.38]$

$1.66[0.49,2.83]$

$0.44[-0.47,1.36]$

$0.87[0.61,1.13]$

$0.79[0.54,1.04]$

$1.00[0.50,1.50]$

$0.72[0.22,1.22]$

$0.85[0.45,1.24]$

$1.34[0.61,2.07]$

$1.66[0.99,2.34]$

$1.87[0.66,3.08]$

$1.47[0.06,2.87]$

$1.21[0.11,2.30]$

$1.68[1.21,2.14]$

$1.19[0.84,1.53]$

$1.23[0.56,1.91]$

$1.17[0.26,2.08]$

$1.58[0.85,2.31]$

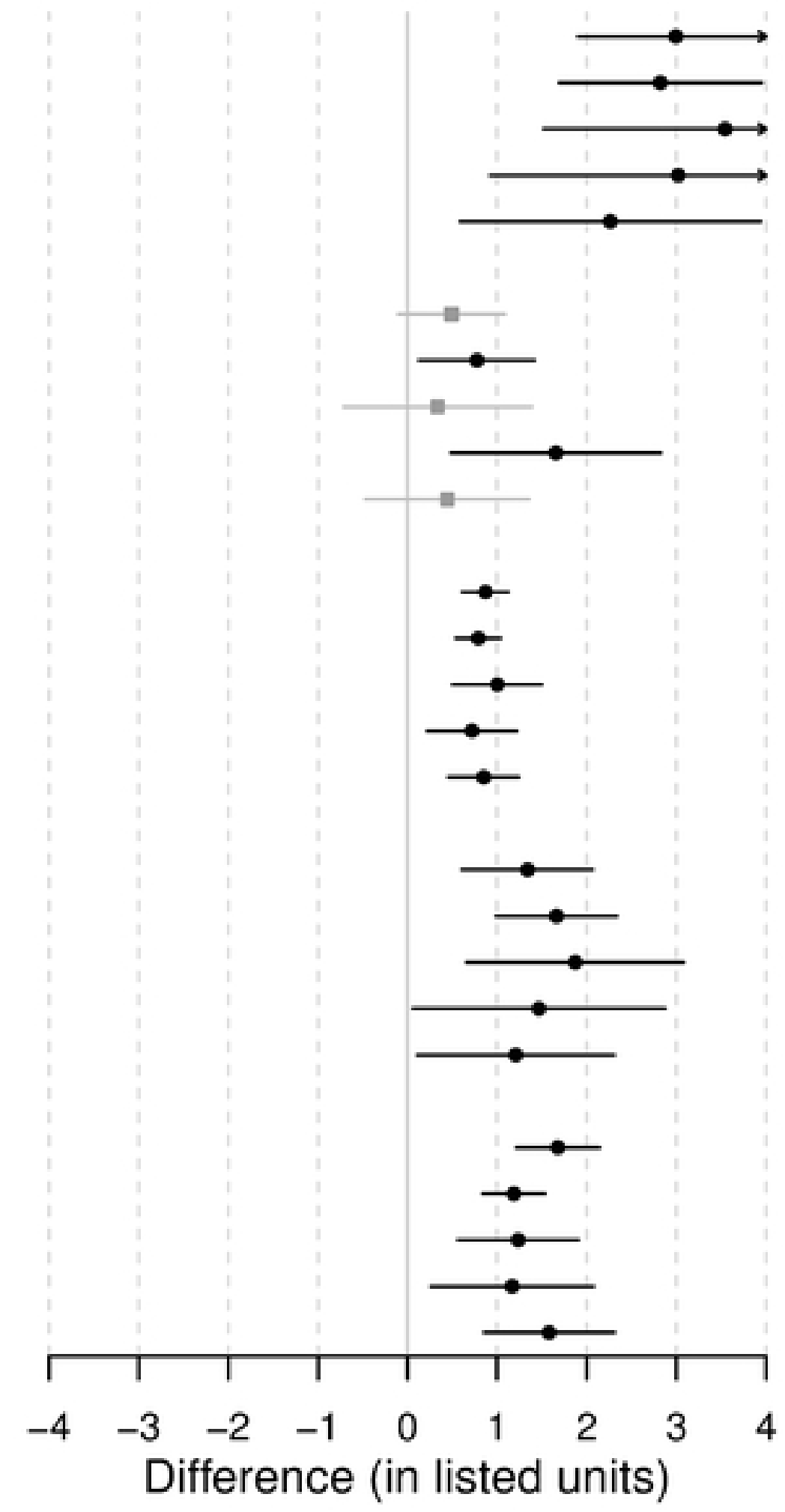

Figure $2 \mathrm{a}$ 


\section{Figure 2b: Effect of 1 additional drink/day}

Cholesterol ( $\mathrm{mmol} / \mathrm{L})$

all

male

female

current smokers

never-smokers

LDL ( $\mathrm{mmol} / \mathrm{L})$

all

male

female

current smokers never-smokers

$\mathrm{HDL}(\mathrm{mmol} / \mathrm{L})$

all

male

female

current smokers

never-smokers

Triglycerides $(\mathrm{mmol} / \mathrm{L})$

male

female

current smokers

never-smokers

HbA1C ( $\mathrm{mmol} / \mathrm{mol})$

all

male

female

current smokers

never-smokers

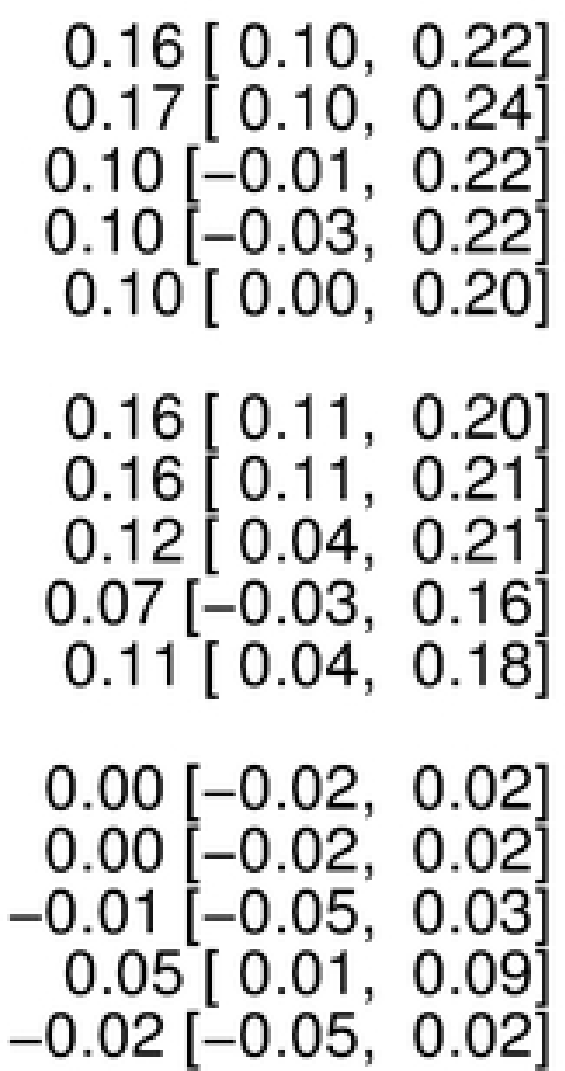

$-0.06[-0.12,0.00]$

$-0.02[-0.09,0.05]$

$-0.08[-0.17,0.00]$

$-0.10[-0.22,0.03]$

$-0.02[-0.10,0.06]$

$-0.42[-0.78,-0.06]$

$-0.09[-0.53,0.36]$

$-0.84[-1.41,-0.27]$

$-0.63[-1.40,0.14]$

$-0.59[-1.10,-0.08]$

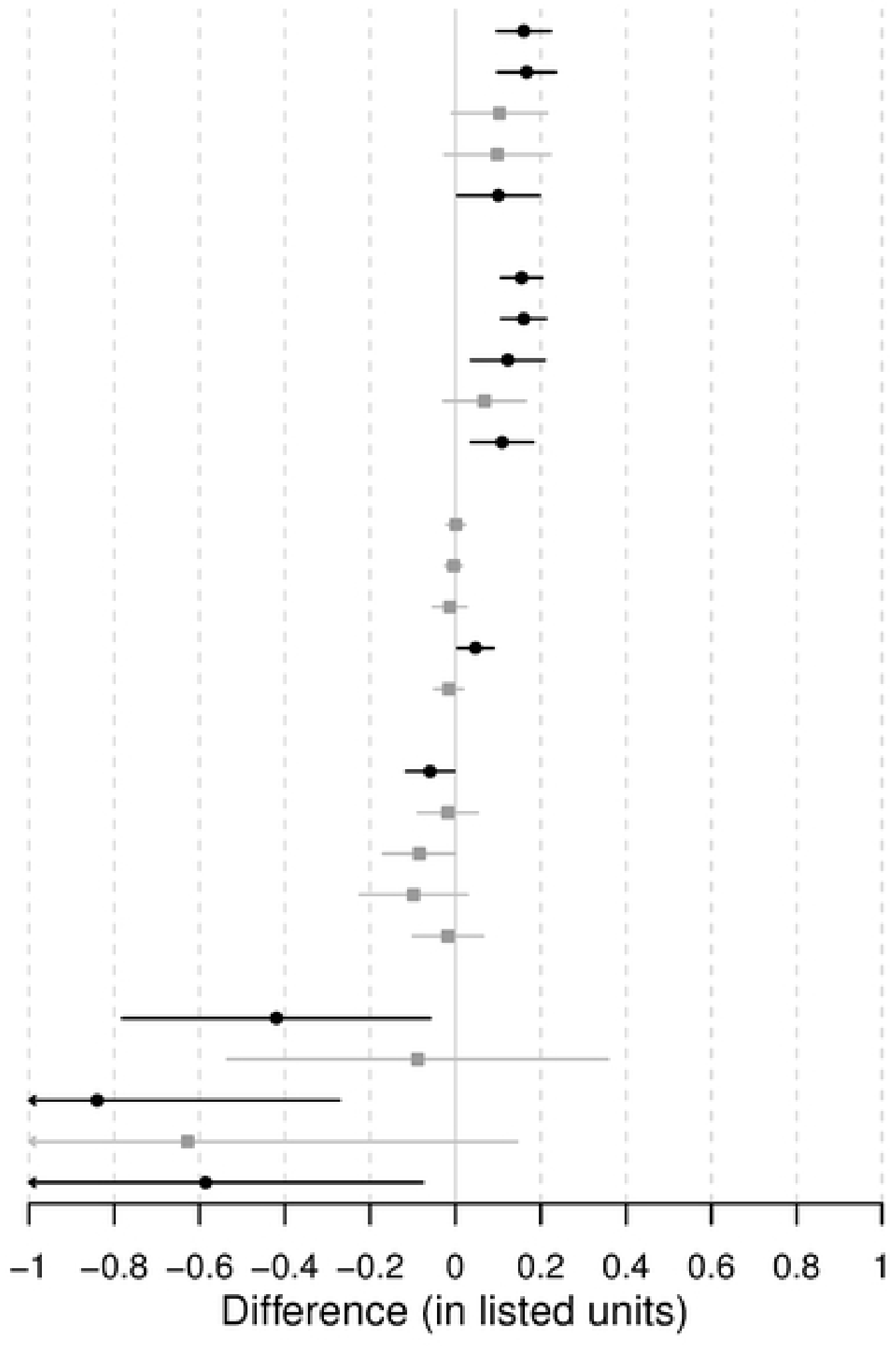

Figure $2 b$ 


\section{Myocardial infarction}

all

male

female

current smokers

Stroke

\section{all}

male

female

current smokers

never-smokers

Ischemic stroke

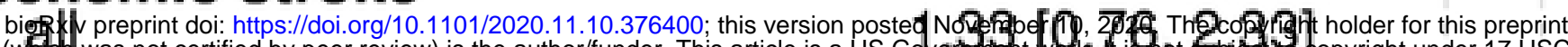

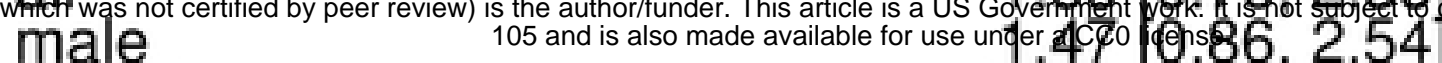

female

current smokers

never-smokers

Hemmorhagic stroke

all

male

female

current smokers

never-smokers

Heart failure

all

male

female

current smokers

never-smokers

Atrial fibrillation

all

male

female

current smokers never-smokers

Type 2 diabetes

male

female

current smokers

never-smokers

Any cardiovascular disease all

male

female

current smokers

never-smokers

All-cause death

all

male

female

current smokers

never-smokers
$1.50[1.15,1.96]$

$1.581 .24,2.00$

$1.060 .54,2.08$

$1.090 .71,1.66$

$1.66[1.01,2.73]$

1.52 [1.04, 2.21].

$1.481 .03,2.15$

$1.500 .70,3.23$

$1.150 .64,2.06$

$1.47[0.78,2.78]$
$0.960 .30,3.12$

$0.730 .34,1.56$

$1.35[0.50,3.60]$

$1.82[0.83,4.01]$

$1.600 .71,3.61$

$2.170 .47,9.94$

$1.450 .41,5.10$

$2.34[0.58,9.42]$

$1.50[0.97,2.31]$

1.76 1.17, 2.66

0.77 0.30, 2.00

$1.290 .66,2.55$

$1.43[0.64,3.21]$

$1.27[0.97,1.65$

$1.351 .05,1.73$

$1.040 .57,1.88$

$1.220 .72,2.06$

1.20 [0.76, 1.89]

$1.26[0.97,1.65]$

$1.311 .01,1.69$

$1.140 .65,2.02$

$1.020 .63,1.64$

1.48 [0.92, 2.38]

$1.43[1.19,1.72]$

$1.561 .31,1.86$

$1.070 .71,1.59$

$1.270 .92,1.75$

1.38 [1.01, 1.90]

$1.41[1.06,1.88]$

$1.651 .24,2.20$

$0.920 .52,1.63$

$1.100 .74,1.63$

$0.83[0.51,1.37]$
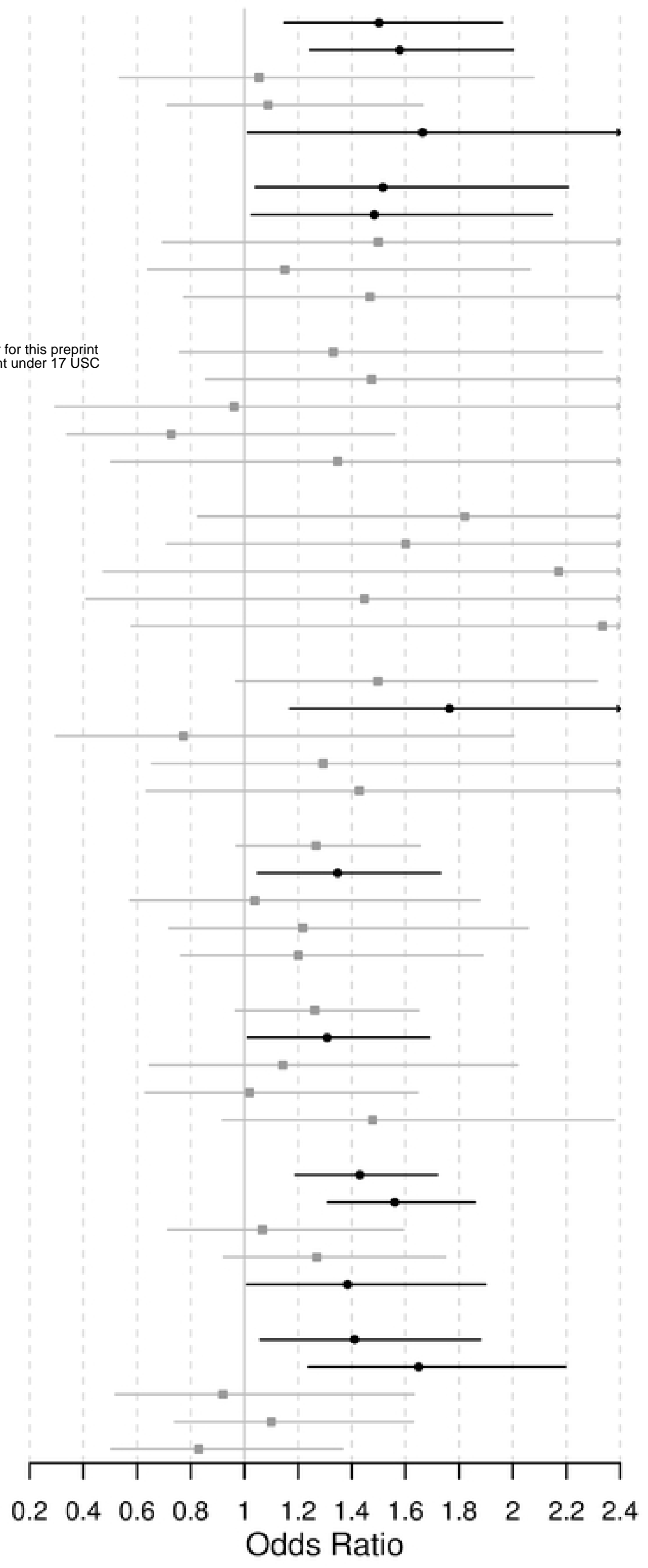

Figure $2 c$ 
Observational analysis effect sizes on cardiometabolic factors

(reference $=$ non-drinkers)

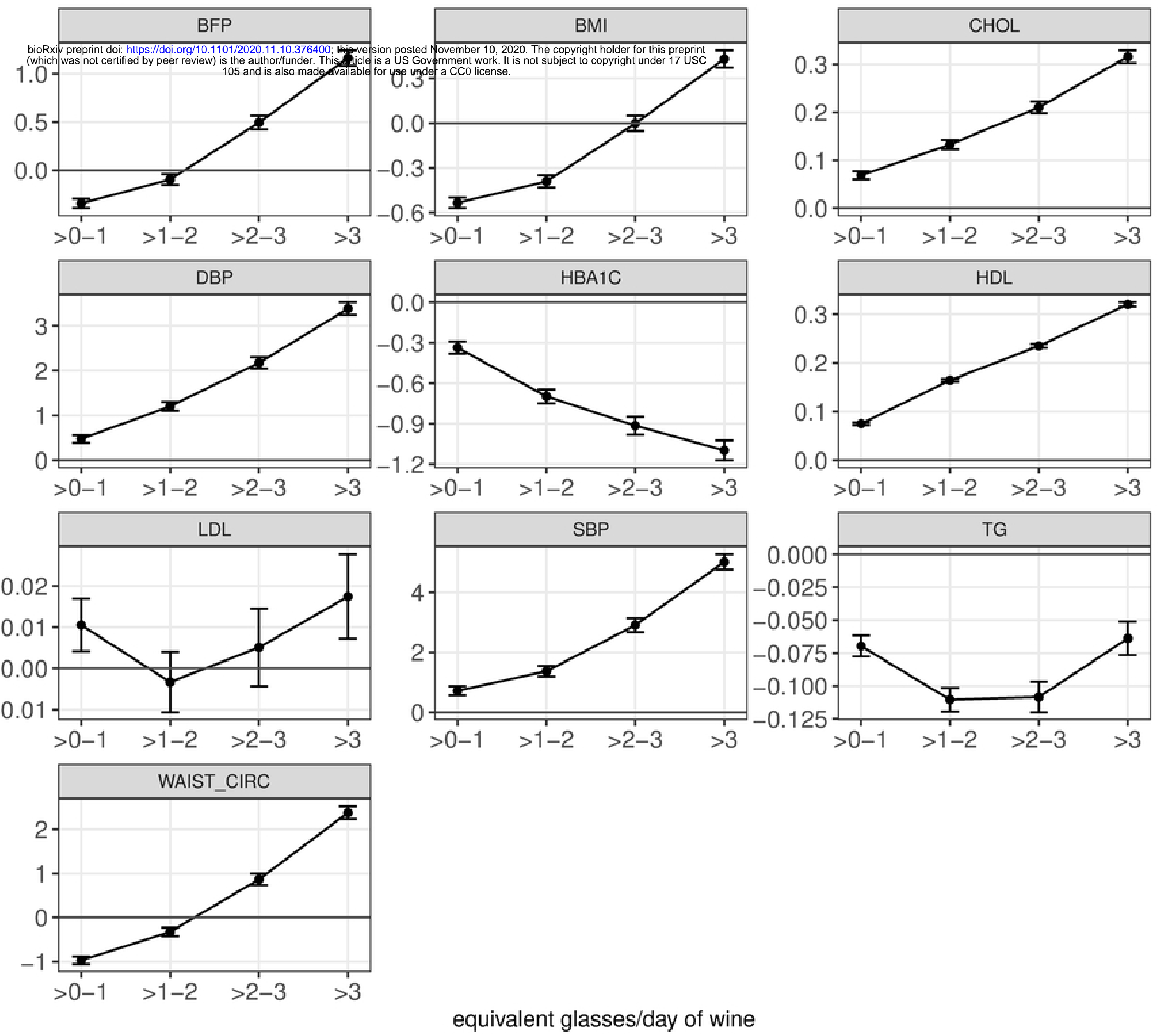

Figure S4-1 
Observational analysis hazard ratio for events and odds ratio for diabetes (reference $=$ non-drinkers)
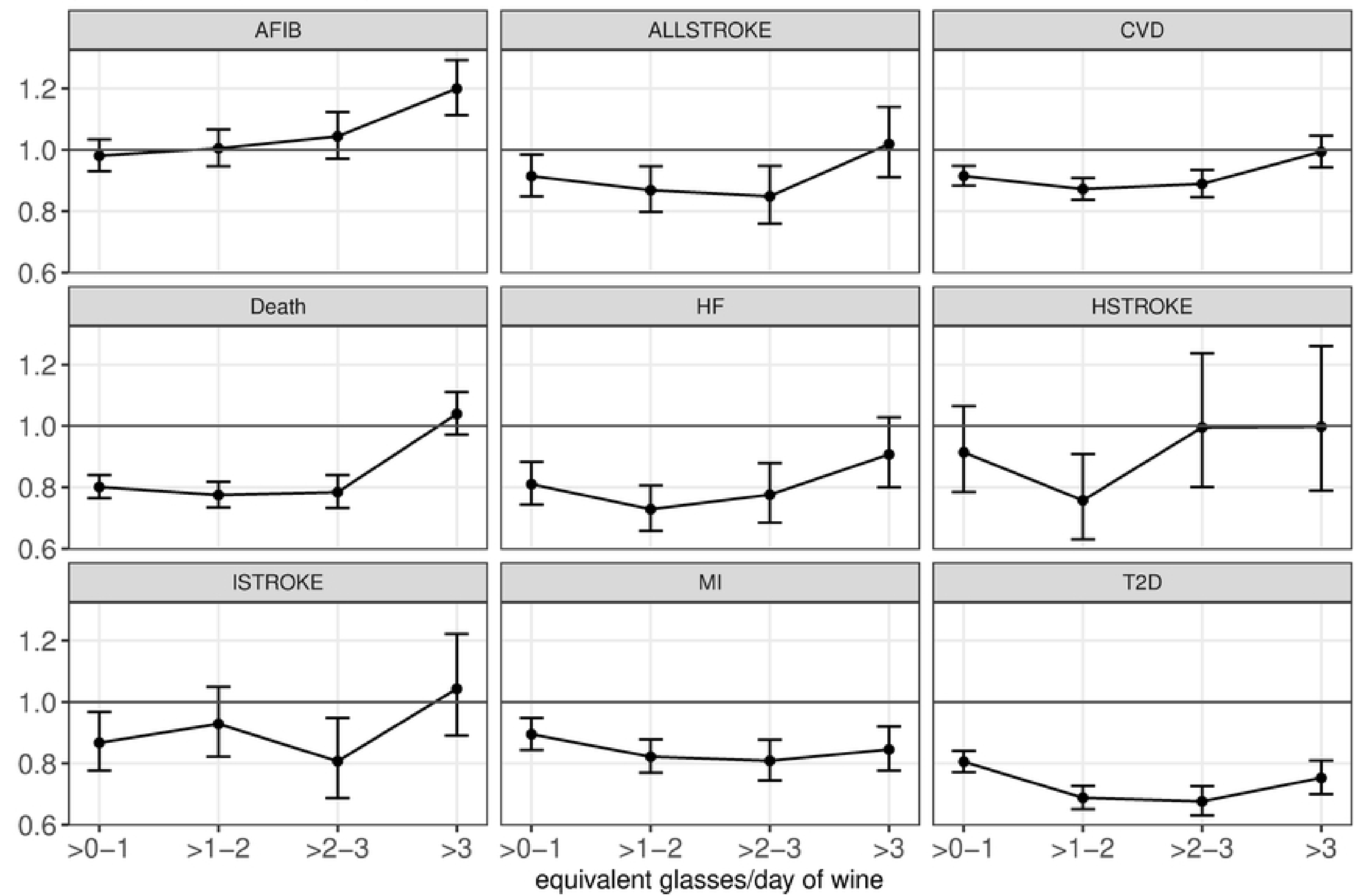

Figure S4-2 